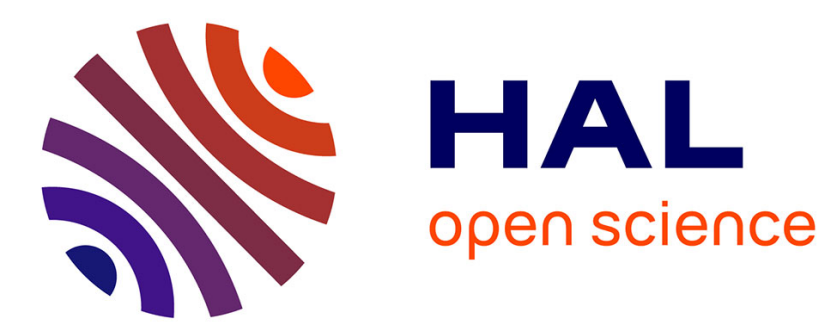

\title{
Undoped and Nd3+ doped Si-based single layers and superlattices for photonic applications
}

Larysa Khomenkova, Christophe Labbé, Xavier Portier, Marzia Carrada, Fabrice Gourbilleau

\section{- To cite this version:}

Larysa Khomenkova, Christophe Labbé, Xavier Portier, Marzia Carrada, Fabrice Gourbilleau. Undoped and $\mathrm{Nd} 3+$ doped Si-based single layers and superlattices for photonic applications. physica status solidi (a), 2013, 210 (8), pp.1532-1543. 10.1002/pssa.201200942 . hal-00835886

\section{HAL Id: hal-00835886 https://hal.science/hal-00835886}

Submitted on 26 Jun 2018

HAL is a multi-disciplinary open access archive for the deposit and dissemination of scientific research documents, whether they are published or not. The documents may come from teaching and research institutions in France or abroad, or from public or private research centers.
L'archive ouverte pluridisciplinaire HAL, est destinée au dépôt et à la diffusion de documents scientifiques de niveau recherche, publiés ou non, émanant des établissements d'enseignement et de recherche français ou étrangers, des laboratoires publics ou privés. 


\title{
Undoped and $\mathrm{Nd}^{3+}$ doped Si-based single layers and superlattices for photonic applications
}

\author{
Larysa Khomenkova*1†, Christophe Labbé1, Xavier Portier', Marzia Carrada², and Fabrice Gourbilleau' \\ ${ }^{1}$ CIMAP (CEA/CNRS/Ensicaen/UCBN), 6 Boulevard Marechal Juin, 14050 Caen, France \\ ${ }^{2}$ CEMES/CNRS, Université de Toulouse, 29 rue J. Marvig, 31055 Toulouse, France
}

Keywords: photoluminescence, rare-earth ions, RF magnetron sputtering, silicon nanostructures

\begin{abstract}
*Corresponding author: e-mail: larysa.khomenkova@ensicaen.fr, Phone: +33 231452671, Fax: +33 231452655
${ }^{\dagger}$ Permanent address: V. Lashkaryov Institute of Semiconductor Physics, 45 Pr. Nauky, 03028 Kyiv, Ukraine;

e-mail khomenkova@rambler.ru
\end{abstract}

\begin{abstract}
This work presents the benefits of the superlattice approach to control light emission properties of materials with $\mathrm{Si}$ nanoclusters and rare-earth ions. The undoped and $\mathrm{Nd}^{3+}$-doped both Si-rich- $\mathrm{SiO}_{2}$ single layers and $\mathrm{Si}$-rich- $\mathrm{SiO}_{2} / \mathrm{SiO}_{2}$ superlattices were grown by radio frequency magnetron sputtering. Their properties were investigated by means of spectroscopic ellipsometry, Fourier infrared transmission spectroscopy, transmission electron microscopy, and photoluminescence (PL) methods versus deposition conditions, annealing treatment, and superlattice design (doping and thickness of alternated sublayers). An intense $\mathrm{Nd}^{3+}$ emission from as-deposited single
\end{abstract}

1 Introduction Nowadays, continuous increase of the demand for energy saving stimulates not only the elaboration of novel materials and devices on their basis, but also gives new impact for development of effective approaches allowing significant improvement of the electrical and optical parameters of already known materials. The main bottleneck of Si-core CMOS technology was the indirect infrared bandgap of bulk crystalline silicon, hampered it to act as light emitter and to develop fully Si-based photonic devices.

Much effort was straightforward for the investigation of different approaches able to overcome this Si drawback. Firstly, "infrared" Si bandgap was modified in porous silicon materials $[1,2]$ by means of chemical or electrochemical etching of bulk Si wafer in HF-based solution. As a result, an efficient "red" emission from such samples was achieved $[1,2]$. Due to quantum confinement effect, the absorption edge of Si nanocrystals or nanoclusters (Si-ncs) was shifted to the visible spectral range that opened not only a possibility layers and superlattices was observed. The lower annealing temperature (below $900{ }^{\circ} \mathrm{C}$ ) of the single layers and superlattices favors the formation of amorphous Si clusters that act as effective sensitizers of rare-earth ions. The highest $\mathrm{Nd}^{3+} \mathrm{PL}$ intensity was achieved after a conventional annealing at about 600-800 ${ }^{\circ} \mathrm{C}$ in nitrogen flow for all samples. Crystallized Sinanoclusters were formed in $\mathrm{Si}$-rich- $\mathrm{SiO}_{2}$ single layers upon annealing at $1000-1100{ }^{\circ} \mathrm{C}$, whereas their formation in the superlattices occurred at higher temperatures $\left(1100-1150{ }^{\circ} \mathrm{C}\right)$. The mechanism of Nd ions' excitation via energy transfer from Si-nanoclusters and/or matrix defects, if any, is discussed. to create light-emitting devices, but also to improve the performance of Si-based solar cells [3].

Among different Si-based nanostructured materials, $\mathrm{Si}$ ncs embedded in $\mathrm{SiO}_{2}$ host attract much attention. Their optical properties are tuned by the mean size of the Si-ncs [4, 5], whereas microelectronic applications of these materials demand the control of the Si-ncs density [6,7].

Besides chemical and/or electrochemical etching of bulk $\mathrm{Si}$ wafers, other fabrication approaches such as ion implantation [8], electron beam evaporation [9], reactive evaporation $[5,10,11]$, chemical vapor deposition $[7,12]$, sputtering $[6,13-16]$, etc. were used to produce Si-based nanostructures. Usually, the formation of Si-ncs is a two-step process. At first, the $\mathrm{Si}-$ rich- $\mathrm{SiO}_{2}$ (SRSO) single layer is fabricated and then, high temperature annealing is used for Si-ncs formation via a phase separation process [8-16].

In spite of many promising results obtained for different SRSO materials [4-16], the Si-ncs density and their sizes 
cannot be tuned independently using single layer approach. Meanwhile, a fine control of the Si-ncs distribution is required to monitor the electronic and optical properties of future Si-ncs-based devices. In this regard, a superlattice approach (when SRSO layers are alternated with insulating barrier sublayers) appears as an effective tool. In this case, a physical confinement of the Si-ncs sizes is obtained by varying the SRSO layer thickness, whereas excess Si content controls the Si-ncs number. As a consequence, more functionalities of Si-ncs-based materials can be considered.

In most cases, the role of alternating sublayers is played by the $\mathrm{SiO}_{2}$ ones $[4-14,17,18]$. They suppress the outdiffusion of $\mathrm{Si}$ atoms from SRSO layers during a phase separation process, favoring the lateral diffusion for Si-ncs formation and, as a consequence, a narrower Si-ncs size distribution is achieved. In spite of this achievement, it is still surprising that an application of superlattice structures to obtain an emission from rare-earth ions is not well addressed.

It is known that absorption cross-section of rare-earth ions is about $10^{-18}-10^{-20} \mathrm{~cm}^{-2}$ for $4 \mathrm{f}-4 \mathrm{f}$ transitions and about $10^{-12} \mathrm{~cm}^{-2}$, for $4 \mathrm{f}-5 \mathrm{~d}$ ones [19]. However, these latter are observed in UV and vacuum UV regions, restricting their use for many applications. Thus, more effective excitation of $4 \mathrm{f}-4 \mathrm{f}$ transitions requires a host enabling excitation via energy transfer. In this regard, Si-ncs offer significant enhancement of the activity of rare-earth

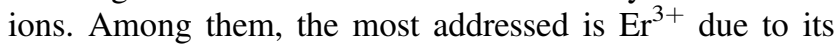
promising application for optical communication $[19,20]$. A lot of efforts were concentrated to obtain efficient emission from $\mathrm{Er}^{3+}$-doped $\mathrm{Si}$-rich- $\mathrm{SiO}_{2}$ single layers $[21,22]$. The $\mathrm{Si}-$ ncs incorporation allows increasing of absorption crosssection of $\mathrm{Er}^{3+}$ ions from $10^{-21} \mathrm{~cm}^{-2}[19,23]$ up to $10^{-16} \mathrm{~cm}^{-2}$ [24-27] due to effective energy transfer from Si-ncs towards $\mathrm{Er}^{3+}$ ions. For this purpose, visible broadband excitation was used offering safe applications of these materials. In spite of these results, a superlattice approach was not well addressed. Only a few works reported an efficient $\mathrm{Er}^{3+}$ emission in the green and infrared spectral ranges $[28,29]$. Unfortunately, the Si-based superlattices doped with other rare-earth ions $\left(\mathrm{Tm}^{3+}, \mathrm{Nd}^{3+}\right.$, etc.) are not well considered $[30,31]$. Meanwhile, the $\mathrm{Nd}^{3+}$ doped structures along with $\mathrm{Er}^{3+}$-doped ones could find a wide application for medicine and communication technologies as it was shown for $\mathrm{Nd}^{3+}$ doped glasses [32] or single $\mathrm{Nd}^{3+}$ doped SRSO films [31, 33, 34].

This paper reports on the properties of $\mathrm{SRSO} / \mathrm{SiO}_{2}$ superlattices produced by RF magnetron sputtering. The effect of fabrication conditions and post-fabrication processing is analyzed in terms of formation of size- and density-controlled Si-ncs. The microstructure evolution, optical, and light emitting properties versus annealing conditions are discussed. Apart from un-doped $\mathrm{SRSO} / \mathrm{SiO}_{2}$ superlattices, their $\mathrm{Nd}^{3+}$ doped counterparts are analyzed. An efficient emission from $\mathrm{Nd}-\mathrm{SRSO} / \mathrm{SiO}_{2}$ superlattices submitted to lower-temperature annealing treatment is demonstrated. The analysis of $\mathrm{Nd}^{3+}$ ions' excitation mechanism (i.e., their interaction with Si-ncs and/or matrix defects, if any) is discussed.
2 Experimental details The samples were fabricated by radio frequency magnetron sputtering. Prior to deposition, the wafers were cleaned in a $10 \% \mathrm{HF}$ water solution, rinsed in de-ionized water, and dried in $\mathrm{N}_{2}$ flow. They were immediately placed in the "load-lock" chamber of deposition unit. Such cleaning procedure allows hydrogen-terminated Si surface to be obtained [35]. This step is important because thermal $\mathrm{SiO}_{2}$ can affect the growth kinetics of SRSO layers and the properties of future thin SRSO layers via presence of some stresses between the film and the substrate [20].

In this work, the samples (either single layers or superlattices) were deposited on 2-inches p-type $\mathrm{Si}$ substrates kept at $500{ }^{\circ} \mathrm{C}$. The substrate rotation during deposition run allowed the fabrication of homogeneous samples. The total pressure of pure argon plasma was fixed at 3 mTorr. Other main deposition conditions are given in Table 1.

The $\mathrm{SiO}_{2}$ layers were grown by sputtering of $\mathrm{SiO}_{2}$ target. The SRSO ones were deposited by simultaneous cosputtering of $\mathrm{SiO}_{2}$ and $\mathrm{Si}$ cathodes. The $\mathrm{Si}$ excess was monitored via RF power density applied on the Si cathode (RFP-Si) at other constant conditions. Doping of the samples with $\mathrm{Nd}^{3+}$ ions was performed during deposition process via simultaneous sputtering of $\mathrm{Nd}_{2} \mathrm{O}_{3}$ target along with $\mathrm{Si}$ and $\mathrm{SiO}_{2}$ ones.

The variation of $\mathrm{Nd}^{3+}$ content in the samples was monitored via a $\mathrm{RFP}-\mathrm{Nd}_{2} \mathrm{O}_{3}$ applied on this cathode. The $\mathrm{Nd}^{3+}$ content was estimated by means of Rutherford backscattering method. It was observed an increase of doping level from $[\mathrm{Nd}]=8 \times 10^{19}$ at $\mathrm{cm}^{-3}\left(\mathrm{RFP}-\mathrm{Nd}_{2} \mathrm{O}_{3}\right.$ $=0.29 \mathrm{~W} \mathrm{~cm}^{-2}$ ) up to $[\mathrm{Nd}]=10^{21} \mathrm{at} \mathrm{cm}^{-3}$ (for RFP$\mathrm{Nd}_{2} \mathrm{O}_{3}=0.59 \mathrm{~W} \mathrm{~cm}^{-2}$ ). The deposition time was tuned to grow the samples (as single layers as superlattices) with a thickness of about $120 \mathrm{~nm}$.

For superlattices, SRSO layer thickness was kept at about $3 \mathrm{~nm}$, whereas the $\mathrm{SiO}_{2}$ one was in the range of 1.5$5.0 \mathrm{~nm}$. The number of stacks in the structures was monitored to keep a total thickness of about $120 \mathrm{~nm}$. However, it is worth to point that the results will be mainly described for the samples made of 20 periods of 3-nm$\mathrm{SRSO} / 3-\mathrm{nm}-\mathrm{SiO}_{2}$ stack, if any other parameters will not be mentioned.

An annealing treatment of single layers and superlattices was performed in a conventional furnace at $300-1150{ }^{\circ} \mathrm{C}$

Table 1 Deposition conditions for undoped and $\mathrm{Nd}^{3+}$ doped $\mathrm{Si}-$ based samples.

\begin{tabular}{llll}
\hline layer & \multicolumn{2}{l}{$\mathrm{RFP}^{\mathrm{a}}\left(\mathrm{W} \mathrm{cm}^{-2}\right)$} & \\
\cline { 2 - 4 } & $\mathrm{SiO}_{2}$ & $\mathrm{Si}$ & $\mathrm{Nd}_{2} \mathrm{O}_{3}$ \\
\hline $\mathrm{SiO}_{2}$ & $7.40,8.88$ & - & - \\
$\mathrm{SRSO}$ & $7.40,8.88$ & $1.63-2.96$ & - \\
$\mathrm{SRSO}-\mathrm{Nd}$ & $7.40,8.88$ & $1.63-2.96$ & $0.29-0.74$ \\
\hline
\end{tabular}

${ }^{a} \mathrm{RFP}$ is a power density applied for the corresponding cathodes $\left(\mathrm{SiO}_{2}, \mathrm{Si}\right.$, or $\mathrm{Nd}_{2} \mathrm{O}_{3}$. 
during 1-60 min in a nitrogen flow to investigate the formation of $\mathrm{Si}$-ncs and to optimize the $\mathrm{Nd}^{3+}$ emitting parameters.

Spectroscopic ellipsometry was used to determine the thickness and refractive index of the as-deposited samples. The data were collected by means of a Jobin-Yvon ellipsometer (UVISEL) where the incident light was scanned in the 1.5-4.5 eV range under an incident angle of $66.3^{\circ}$. The fitting of the experimental data was performed using DeltaPsi2 software [36]. Hereafter, the $n$ values taken at $1.5 \mathrm{eV}$ will be used for comparison. A Nicolet Nexus Fourier transform infrared (FTIR) spectrometer was used to investigate the infrared absorption spectra of the samples. FTIR spectra were measured under normal and Brewster $\left(65^{\circ}\right)$ angle incidences.

Cross-sectional foils were prepared for TEM examination by a standard mechanical procedure involving grinding, dimpling, and $\mathrm{Ar}^{+}$ion beam thinning until electron transparency. The samples were observed by conventional (CTEM) and high-resolution electron microscopy (HRTEM) using a FEG 2010 JEOL instrument operated at $200 \mathrm{keV}$. EFTEM was carried out on cross-sectional specimens using a field emission TEM, FEI Tecnai ${ }^{\mathrm{TM}}$ F20 microscope operated at $200 \mathrm{kV}$, equipped with a corrector for spherical aberration and a TRIDIEM Gatan Imaging Filter (GIF). This latter technique was used to observe the formation of $\mathrm{Si}$ clusters (crystallized and amorphous). EFTEM images were formed with electrons that are selected by a slit placed in the energy-dispersive plane of the spectrometer with a width of $4 \mathrm{eV}$ centered at $17 \mathrm{eV}$ (Si-plasmon energy).

Photoluminescence (PL) properties of the samples were investigated at room temperature. A $488 \mathrm{~nm}$ line from an Innova 90C coherent $\mathrm{Ar}^{+}$laser was used as the excitation source. This wavelength corresponds to a non-resonant excitation for $\mathrm{Nd}^{3+}$ ions. The PL spectra were recorded in the 500-1150 nm spectral range using a fast Hamamatsu R5108 photomultiplier tube (PMT) after dispersion of the light through a Jobin-Yvon TRIAX 180 monochromator linked with a SRS lock-in amplifier (SP830 DPS) referenced to the chopping frequency of light fixed at $20 \mathrm{~Hz}$. Besides, a liquidnitrogen cooled $\mathrm{Ge}$-detector was used to detect the emission from $\mathrm{Nd}^{3+}$-doped samples corresponding to the intra-4f shell transitions of $\mathrm{Nd}^{3+}$ ions, i.e., from the ${ }^{4} \mathrm{~F}_{3 / 2}$ level to the ${ }^{4} \mathrm{I}_{9 / 2}$ $(0.92 \mu \mathrm{m}),{ }^{4} \mathrm{I}_{11 / 2}(1.06 \mu \mathrm{m})$, and ${ }^{4} \mathrm{I}_{13 / 2}(1.35 \mu \mathrm{m})$ levels. However, it did not allow correct simultaneous detection of visible PL emission from the samples. Thus, in the following, we present the spectra detected with a Hamamatsu R5108 PMT since $0.92 \mu \mathrm{m} \mathrm{Nd}^{3+}$ luminescence transition and the $\mathrm{Si}$ ncs emission can be detected simultaneously. This allowed simultaneous control of the PL properties of Si-ncs and different host defects (if any) and their interaction with $\mathrm{Nd}^{3+}$ ions. Since $0.92 \mu \mathrm{m} \mathrm{Nd}^{3+} \mathrm{PL}$ cannot be excited via bulk $\mathrm{Si}$ bandgap due to its smaller energy, it is obvious that Si-ncs and/ or host defects can be considered as sensitizers of $\mathrm{Nd}^{3+}$ ions. Thus, hereafter the PL spectra in the 500-1000 nm spectral range are presented for all the samples including $\mathrm{Nd}^{3+}$-doped ones.
3 Results and discussion Let us briefly describe the properties of single undoped and $\mathrm{Nd}^{3+}$-doped SRSO layers versus deposition conditions and annealing treatment to demonstrate the best choice for the deposition conditions for Si-based superlattices' fabrication.

3.1 Effect of deposition conditions on the properties of single layers Numerous samples were fabricated with different deposition conditions to calibrate the deposition rate, layer stoichiometry and $\mathrm{Nd}^{3+}$ content (for the case of doped layers) to achieve Sincs formation as well as efficient $\mathrm{Nd}^{3+}$ emission.

The samples stoichiometry was studied by means of spectroscopic ellipsometry (SE) and FTIR methods. The first approach is based on the correlation between the refractive index and Si-enrichment of SRSO layer [37], considering this latter as a heterogeneous mixture of amorphous $\mathrm{Si}$ and $\mathrm{SiO}_{2}$ phases. Variation of $\mathrm{Si}$ content was monitored via the $\mathrm{RF}$ power applied on the $\mathrm{Si}$ target in the range RFP$\mathrm{Si}=1.63-2.96 \mathrm{~W} \mathrm{~cm}^{-2}$. Note that monitoring of deposition time was used to achieve constant thicknesses of the samples. This statement was confirmed by SE data demonstrating the efficient calibration of the deposition conditions. The spectroscopic variation of the refractive index, $n$, was also obtained and the results are presented in Fig. 1a for $n$ taken at $1.5 \mathrm{eV}$ light as a function of RFP-Si.

To estimate the parameter of layers' stoichiometry, $x_{\mathrm{SE}}=[\mathrm{O}] /[\mathrm{Si}]$, from SE data we used the equation:

$$
n=4-2.53 x+0.63 x^{2}
$$

proposed by Dehan et al. [37] for the $n$-value determined at $1.5 \mathrm{eV}$ light energy. It was found the $x_{\mathrm{SE}}$ value decreases

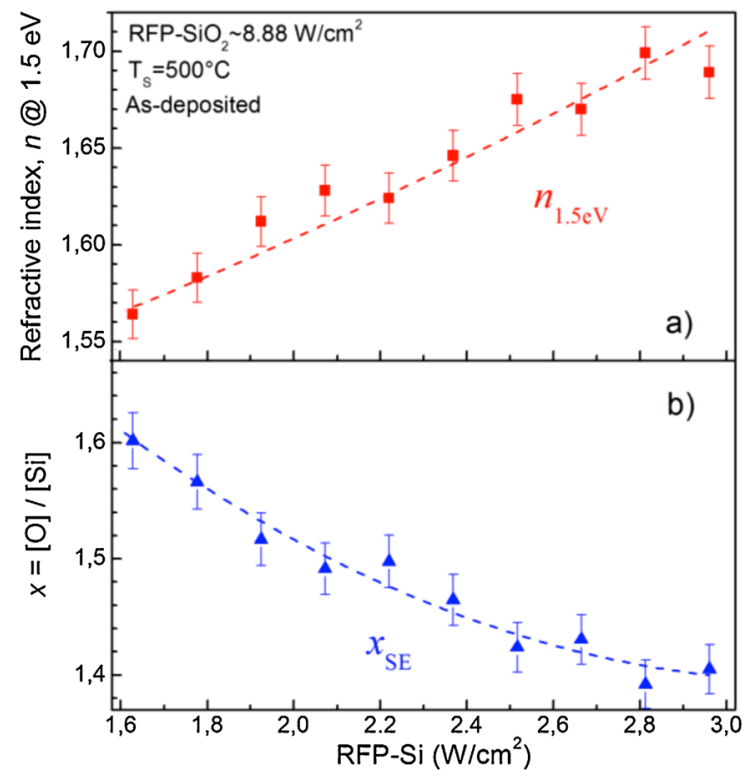

Figure 1 The refractive index, $n$ (taken at $1.5 \mathrm{eV}$ ) (a) and the parameter of layer stoichiometry, $x=[\mathrm{O}] /[\mathrm{Si}]$, of SRSO layers (b) versus RFP-Si. 
from 1.72 down to 1.48 when the RFP-Si increases from $1.63 \mathrm{~W} \mathrm{~cm}^{-2}$ up to $2.96 \mathrm{~W} \mathrm{~cm}^{-2}$ (Fig. 1b).

It is worth to note, that doping of SRSO layers with $\mathrm{Nd}^{3+}$ ions does not affect the refractive index, when RFP- $\mathrm{Nd}_{2} \mathrm{O}_{3}$ is below $0.44 \mathrm{~W} \mathrm{~cm}^{-2}$. However, $n$ increases by $\Delta n \approx 0.02$ when $\mathrm{RFP}-\mathrm{Nd}_{2} \mathrm{O}_{3} \geq 0.59 \mathrm{~W} \mathrm{~cm}{ }^{-2}$. To explain this behavior, one can suppose that co-sputtering of $\mathrm{Nd}_{2} \mathrm{O}_{3}$ target adds in the plasma not only rare-earth ions, but also oxygen ones. It is possible that more $\mathrm{Si}-\mathrm{O}$ bonds are formed due to a chemical activity of oxygen, as well as $\mathrm{Nd}-\mathrm{Si}-\mathrm{O}$ bonds. These latter can favor the appearance of a material with higher refractive index. Taking into account the samples composition and the fact that $\mathrm{SiO}_{2}$ phase has a lower refractive index $(n=1.45$ at $1.5 \mathrm{eV})$, this increase of refractive index with $\mathrm{RFP}-\mathrm{Nd}_{2} \mathrm{O}_{3}$ can be caused by the formation of small $\mathrm{Nd}-\mathrm{Si}-\mathrm{O}$ and/or $\mathrm{Si}$ agglomerates.

Analysis of FTIR spectra was also used to estimate the stoichiometric parameter $\left(x_{\mathrm{FTIR}}\right)$. In this case, the peak position of $\mathrm{Si}-\mathrm{O} \mathrm{TO}_{3}$ phonon measured for SRSO layers is compared to that obtained for pure $\mathrm{SiO}_{2}$ with equal thickness grown with the same conditions. Besides, the analysis of the shape of FTIR spectra allowed the effect of $\mathrm{Nd}^{3+}$ ion incorporation on the distortion of the SRSO host, if any, to be observed.

It is known that continuous random network of $\mathrm{SiO}_{2}$ consists of corner-coordinated $\mathrm{SiO}_{4}$ tetrahedra and disorder of amorphous structures comes from the $\mathrm{Si}-\mathrm{O}-\mathrm{Si}$ bond angle changes. Usually, $\mathrm{SiO}_{2}$ possesses several vibration modes in the mid-infrared range originating mainly from the motion of oxygen atoms.

Under specific conditions, different $\mathrm{LO}$ and TO phonons of $\mathrm{Si}-\mathrm{O}$ bond can be detected in the $450-1350 \mathrm{~cm}^{-1}$ spectral range: at $1076 \mathrm{~cm}^{-1}\left(\mathrm{TO}_{3}\right)$ and $1256 \mathrm{~cm}^{-1}\left(\mathrm{LO}_{3}\right)$, at $1160 \mathrm{~cm}^{-1}\left(\mathrm{TO}_{4}\right)$ and $1200 \mathrm{~cm}^{-1}\left(\mathrm{LO}_{4}\right)$, at $810 \mathrm{~cm}^{-1}\left(\mathrm{TO}_{2}\right)$ and $820 \mathrm{~cm}^{-1}\left(\mathrm{LO}_{2}\right)$, as well as at $457 \mathrm{~cm}^{-1}\left(\mathrm{TO}_{1}\right)$ and $507 \mathrm{~cm}^{-1}\left(\mathrm{LO}_{1}\right)$ [38-40]. Additional incorporation of Si into $\mathrm{SiO}_{2}$ host leads to the shift of $\mathrm{LO}_{3}$ and $\mathrm{TO}_{3}$ phonons to lower-wave-numbers, as well as an increasing contribution of $\mathrm{LO}_{4}-\mathrm{TO}_{4}$ doublet in the FTIR spectra [40, 46]. Moreover, in the case of high doping level in $\mathrm{SiO}_{2}$ and/or SRSO with rare-earth ions, the broadening of $\mathrm{TO}_{3}$ phonon towards lower wave-numbers is also expected due to the incorporation of heavy ion into $\mathrm{Si}-\mathrm{O}$ bonding similarly to that observed in Ref. [35].

To estimate the $x_{\text {FTIR }}$ value, the layer thickness effect on the $\mathrm{TO}_{3}$ phonon peak position $\left(v_{\mathrm{TO}_{3}}\right)$ has to be also considered. It is known that the decrease of $\mathrm{SiO}_{2}$ layer thickness down to nanometer scale is accompanied by a shift of the peak positions of all vibration bands to lower wave numbers as well as by a decrease in the intensity of $\mathrm{TO}_{4}-\mathrm{LO}_{4}$ phonons that are usually ascribed to disordering of $\mathrm{SiO}_{2}$ matrix [39]. In the case of $\mathrm{LO}_{3}$ and $\mathrm{TO}_{3}$ phonons, this shift is about $\Delta v \sim 25-30 \mathrm{~cm}^{-1}$ [41]. Moreover, the detection of $\mathrm{LO}_{3}$ phonon is usually considered as an evidence of the formation of perfect $\mathrm{Si} / \mathrm{SiO}_{2}$ interface [42]. Thus, comparison between samples with similar thicknesses grown with different deposition conditions allows the effect of silicon and rare-earth ions incorporation on the microstructure of the layers to be revealed.

FTIR spectra of as-deposited SRSO layers, measured under normal incidence of the light excitation, are presented in Fig. 2a. The intense absorption band around $1000 \mathrm{~cm}^{-1}$ corresponds to the asymmetric stretching vibration of the oxygen atom in its twofold coordinated bridging bonding site $\left(\mathrm{TO}_{3}\right.$ phonon) [43]. As one can see, when the RFP-Si increases, the $\mathrm{TO}_{3}$ phonon $\left(I_{\mathrm{TO}_{3}}\right)$ peak intensity decreases accompanied by its broadening and by a shift of its position to lower wave-numbers.

This behavior is the evidence of higher $\mathrm{Si}$ incorporation into $\mathrm{SiO}_{2}$ host resulting in a decrease of the number of $\mathrm{Si}-\mathrm{O}$ bonds as well as in the broadening of $\mathrm{TO}_{3}$ phonon (Fig. 2a). The FTIR spectra detected under Brewster incidence of the light excitation show a significant decrease of the $\mathrm{LO}_{3}$ phonon peak intensity, with a concomitant increase of the $\mathrm{LO}_{4}-\mathrm{TO}_{4}$ doublet contribution (Fig. 2b). Since the layers investigated have close thicknesses, this behavior of FTIR spectra can be explained by higher $\mathrm{Si}$ incorporation into $\mathrm{SiO}_{2}$ host.

Based on the FTIR data, one can estimate the stoichiometric parameter $\left(x_{\mathrm{FTIR}}=[\mathrm{O}] /[\mathrm{Si}]\right)$. For this
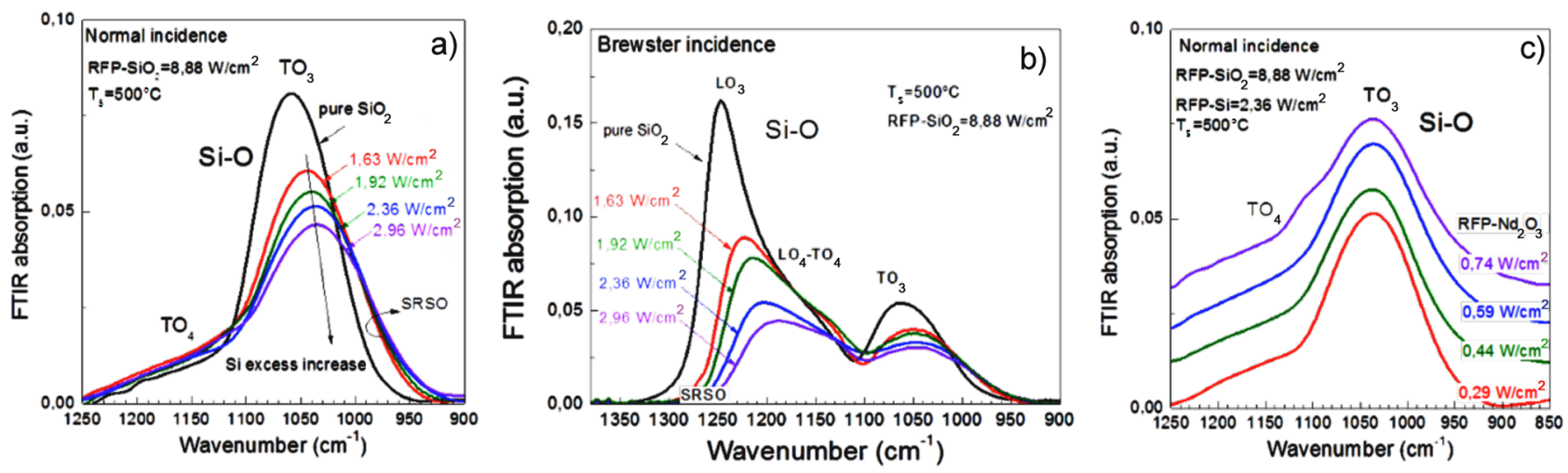

Figure 2 FTIR spectra of as-deposited undoped (a and b) and $\mathrm{Nd}^{3+}$-doped (c) SRSO single layers versus RFP-Si (a and b) and RFP$\mathrm{Nd}_{2} \mathrm{O}_{3}$ (c) values measured at normal (a and c) and Brewster (b) incidence of light excitation. Deposition conditions are mentioned in the figures. The spectra for pure $\mathrm{SiO}_{2}$ layer grown with the same conditions are also presented for comparison. 
purpose, a pure $\mathrm{SiO}_{2}$ layer with the same thickness and a refractive index $n=1.45$ (at $1.5 \mathrm{eV}$ ) was grown with the same conditions from the $\mathrm{SiO}_{2}$ target only. The $\mathrm{TO}_{3}$ phonon of pure $\mathrm{SiO}_{2}$ is peaked at $v_{\mathrm{TO}_{3}}=1060 \mathrm{~cm}^{-1}$ (Fig. 2a). This value is lower than that of $\mathrm{TO}_{3}$ phonon $\left(1080 \mathrm{~cm}^{-1}\right)$ usually referenced for thermal $\mathrm{SiO}_{2}[38-43,45]$. This difference in the peak positions can be due to the lower thickness of our $\mathrm{SiO}_{2}$ layer as well as its microstructure caused by the angle of $\mathrm{Si}-\mathrm{O}-\mathrm{Si}$ bonds [41]. This latter has a mean value of about $144^{\circ}$ with a full width at half maximum of about $35^{\circ}$ (i.e., this angle can vary from $125^{\circ}$ up to $180^{\circ}$ ) for stoichiometric amorphous $\mathrm{SiO}_{2}$ layers [44]. The variation of $\mathrm{Si}-\mathrm{O}-\mathrm{Si}$ angle affects the optical properties of $\mathrm{SiO}_{2}$ layers leading to a shift of the $\mathrm{TO}_{3}$ peak position.

Thus, to obtain correct $x_{\text {FTIR }}$ values, we performed this estimate based on the $\mathrm{TO}_{3}$ peak position corresponding to our $\mathrm{SiO}_{2}$ layers, using the equation:

$$
x_{\mathrm{FTIR}}=0.02 v_{\mathrm{TO}_{3}}-19.2
$$

similarly to the approach described in Ref. [45]. Finally, a linear $x$ decrease from 1.67 down to 1.49 was obtained for a RFP-Si variation from $1.63 \mathrm{~W} \mathrm{~cm}^{-2}$ up to $2.96 \mathrm{~W} \mathrm{~cm}^{-2}$. Thus, these data confirm the monitoring of the Si content in SRSO layers via the RFP-Si parameter.

Comparison between $x_{\mathrm{SE}}$ and $x_{\mathrm{FTIR}}$ values obtained from SE and FTIR data shows that they are in good agreement (Table 2). However, higher $x$ values (corresponding to lower Si content) obtained from FTIR data for higher RFP-Si values can be due to the FTIR insensitivity to the $\mathrm{Si}-\mathrm{Si}$ vibration modes inside of some $\mathrm{Si}$ agglomerates.

Doping of SRSO layers with $\mathrm{Nd}^{3+}$ ions with RFP$\mathrm{Nd}_{2} \mathrm{O}_{3} \leq 0.44 \mathrm{~W} \mathrm{~cm}^{-2}$ at constant other conditions does not change the FTIR spectra significantly (Fig. 2c). However, for RFP- $\mathrm{Nd}_{2} \mathrm{O}_{3} \geq 0.59 \mathrm{~W} \mathrm{~cm}{ }^{-2}$, FTIR spectra show a $\mathrm{TO}_{3}$ phonon peak broadening due to the formation of $\mathrm{Si}-\mathrm{O}-\mathrm{Nd}$ bonds. Note that $\mathrm{Nd}^{3+}$ doping does not affect the $\mathrm{TO}_{3}$ peak position. The appearance of small feature at about $1110-1120 \mathrm{~cm}^{-1}$ can be due to the formation of $\mathrm{Si}-\mathrm{O}$ bonds in $\mathrm{Si}$ agglomerates (similarly to the $\mathrm{Si}-\mathrm{O}$ presence in bulk crystalline Si materials).

Table 2 The parameter of stoichiometry, $x=[\mathrm{O}] /[\mathrm{Si}]$, obtained from spectroscopic ellipsometry $\left(x_{\mathrm{SE}}\right)$ and FTIR $\left(x_{\mathrm{FTIR}}\right)$ data for SRSO samples grown with different RFP-Si values.

\begin{tabular}{|c|c|c|c|c|}
\hline \multirow[t]{2}{*}{$\mathrm{RFP}_{-\mathrm{Si}^{\mathrm{a}}\left(\mathrm{W} / \mathrm{cm}^{2}\right)}$} & \multicolumn{2}{|l|}{ SE } & \multicolumn{2}{|l|}{ FTIR } \\
\hline & $n_{1.5 \mathrm{eV}}$ & $x_{\mathrm{SE}}$ & $\nu_{\mathrm{TO}_{3}}$ & $x_{\text {FTIR }}$ \\
\hline 1.63 & 1.56 & 1.60 & 1043.5 & 1.67 \\
\hline 1.92 & 1.61 & 1.51 & 1041.5 & 1.63 \\
\hline 2.36 & 1.65 & 1.46 & 1035.5 & 1.51 \\
\hline 2.96 & 1.69 & 1.41 & 1034.5 & 1.49 \\
\hline
\end{tabular}

${ }^{a}$ RFP is a power density applied on the Si cathode; SE, spectroscopic ellipsometry.
3.2 Effect of annealing treatment of single layer properties Let us discuss the effect of thermal treatment on the evolution of SRSO layers and Si-ncs formation. It is known that annealing of SRSO layers at high temperature induces a phase separation between $\mathrm{Si}$ and $\mathrm{SiO}_{2}$ phases $[5,13,16,24,34]$. This process is reflected by a shift of $\mathrm{TO}_{3}$ and $\mathrm{LO}_{3}$ peak positions towards higher wave-numbers (Fig. 3a, c, and d), reaching the position of their counterparts corresponding to pure $\mathrm{SiO}_{2}$ (1075-1080 and 1255$1260 \mathrm{~cm}^{-1}$, respectively) [37, 39]. Besides, the $\mathrm{LO}_{3}$ intensity increases, whereas the contribution of $\mathrm{LO}_{4}-\mathrm{TO}_{4}$ doublet decreases, revealing an improvement of matrix ordering [46] (Fig. 3).

Usually, the preferable increase of the $\mathrm{LO}_{3}$ peak intensity $\left(I_{\mathrm{LO}_{3}}\right)$ with respect to that of $\mathrm{TO}_{3}$ phonon $\left(I_{\mathrm{TO}_{3}}\right)$ is assigned to the nucleation and crystallization of the Si-ncs. Based on this assumption, one can see that in our case a phase separation begins at moderate temperatures (below $800{ }^{\circ} \mathrm{C}$ ) evidenced by the shift of $\nu_{\mathrm{TO}_{3}}$ and $\nu_{\mathrm{LO}_{3}}$ from 1048 to $1065 \mathrm{~cm}^{-1}$ and from 1200 to $1225 \mathrm{~cm}^{-1}$, respectively (Fig. 3a and b). Along with this, the $I_{\mathrm{LO}_{3}} / I_{\mathrm{TO}_{3}}$ ratio is still unchangeable, giving an assumption about the reconstruction of $\mathrm{Si}-\mathrm{O}$ and $\mathrm{Si}-\mathrm{Si}$ bonds in $\mathrm{Si}-\mathrm{SiO}_{4-x}$ and $\mathrm{Si}-\mathrm{Si}_{x}$ tetrahedra.

The gradual increase of the $I_{\mathrm{LO}_{3}} / I_{\mathrm{TO}_{3}}$ value for $T_{\mathrm{A}}=800-1000{ }^{\circ} \mathrm{C}$ is consistent with the formation of Sinuclei that is more prominent for higher $T_{\mathrm{A}}$ values. The shift of both phonon peaks to higher wave-numbers up to $v_{\mathrm{TO}_{3}}=1078 \mathrm{~cm}^{-1}$ and $\nu_{\mathrm{LO}_{3}}=1250 \mathrm{~cm}^{-1}$ is observed. For $T_{\mathrm{A}}=1050-1150{ }^{\circ} \mathrm{C}$, the variations of $\nu_{\mathrm{TO}_{3}}$ and $\nu_{\mathrm{LO}_{3}}$ are negligible, whereas $I_{\mathrm{LO}_{3}} / I_{\mathrm{TO}_{3}}$ increases significantly. Such a behavior is also indicative of the formation of Si-ncs and their crystallization at such annealing temperatures [41, 46].

Comparison between FTIR spectra of as-deposited undoped and $\mathrm{Nd}^{3+}$-doped SRSO samples (grown with the same RFP-Si and RFP- $\mathrm{Nd}_{2} \mathrm{O}_{3}<0.44 \mathrm{~W} \mathrm{~cm}^{-2}$ ) revealed their similarity, which is also observed for all samples annealed at $1100{ }^{\circ} \mathrm{C}$ (Fig. 3c). These samples contain about $[\mathrm{Nd}] \approx 10^{20}$ at $\mathrm{cm}^{-3}$. Considering the FTIR method sensitivity, one can suppose the absence or negligible formation of $\mathrm{Nd}-\mathrm{Si}-\mathrm{O}$ bonds (i.e., Nd-clustering) in such layers (Fig. 3c). By contrast, the increase of $\mathrm{RFP}-\mathrm{Nd}_{2} \mathrm{O}_{3}$ up to $0.74 \mathrm{~W} \mathrm{~cm}^{-2}$ leads to the broadening of $\mathrm{TO}_{3}$ phonon and an increase of the $\mathrm{LO}_{4}-\mathrm{TO}_{4}$ contribution not only for asdeposited samples, but also for annealed ones (Fig. 3d and e). An additional vibration band (or shoulder) in the 900$980 \mathrm{~cm}^{-1}$ spectral range appears. This is an evidence of the formation of $\mathrm{Nd}-\mathrm{Si}-\mathrm{O}$ bonds and $\mathrm{Nd}^{3+}$ clustering in SRSO host. The increase of the $\mathrm{Nd}^{3+}$ content up to $[\mathrm{Nd}] \approx 10^{21}$ at $\mathrm{cm}^{-3}$ makes such clustering more probable (Fig. $3 \mathrm{c}-\mathrm{e}$ ). Thus, FTIR spectra demonstrate a significant effect of the deposition and post-deposition conditions on microstructure of the samples affecting their optical and luminescent properties.

3.3 PL properties of undoped single layers The as-deposited layers did not demonstrate intense PL emission. 

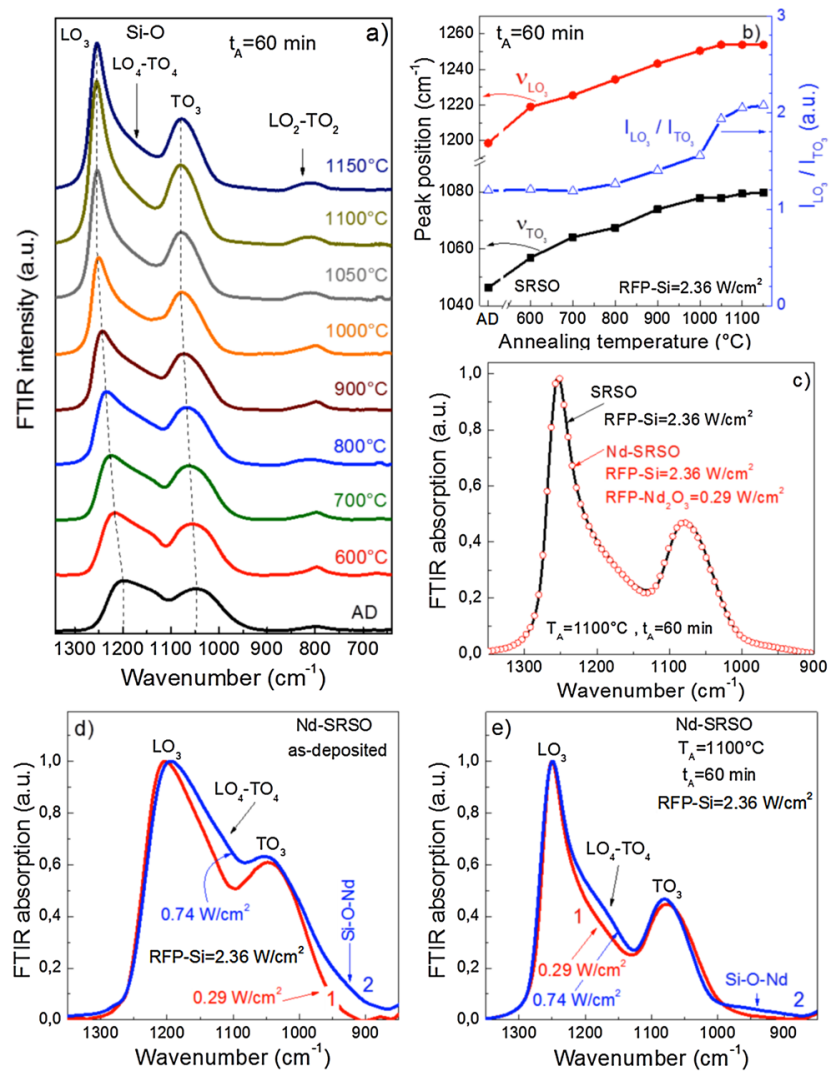

Figure 3 Evolution of FTIR spectra (a), peak positions of $\mathrm{TO}_{3}$ $\left(v_{\mathrm{TO}_{3}}\right)$ and $\mathrm{LO}_{3}\left(v_{\mathrm{LO}_{3}}\right)$ phonons as well as $I_{\mathrm{LO}_{3}} / I_{\mathrm{TO}_{3}}$ ratio (b) versus $T_{\mathrm{A}}$ for SRSO layer. (c) FTIR spectra of undoped (solid line) and $\mathrm{Nd}^{3+}$-doped SRSO (circle symbols) layers annealed at $1100{ }^{\circ} \mathrm{C}$. (d and e) FTIR spectra of as-deposited (d) and annealed at $1100{ }^{\circ} \mathrm{C}$ (e) Nd-doped SRSO layers grown RFP- $\mathrm{Nd}_{2} \mathrm{O}_{3}=0.29 \mathrm{~W} \mathrm{~cm}^{-2}(1)$ and $0.74 \mathrm{~W} \mathrm{~cm}^{-2}(2)$, demonstrating a formation of $\mathrm{Si}-\mathrm{O}-\mathrm{Nd}$ complexes for higher Nd content. Spectra were normalized on the $I_{\mathrm{LO}_{3}}$ value. For (a-e) RFP-Si $=2.36 \mathrm{~W} \mathrm{~cm}{ }^{-2}, t_{\mathrm{A}}=60 \mathrm{~min}$. FTIR spectra presented in (a, c-e) were measured under Brewster incidence $\left(65^{\circ}\right)$.

Sometimes, a weak red emission with the PL peak at about $730 \mathrm{~nm}$ was observed (not shown here). In such a case, it can be ascribed to $\mathrm{SiO}_{x}$ defects or some $\mathrm{Si}$ agglomerates formed during deposition at high temperature $\left(500{ }^{\circ} \mathrm{C}\right)$ similarly to the results of Refs. [20, 24, 47]. To form Si-ncs, an annealing at $1100-1150{ }^{\circ} \mathrm{C}$ for $60 \mathrm{~min}$ in nitrogen flow is usually applied [3, 5, 11]. This treatment results also in an appearance of bright emission in the visible spectral range caused by either radiative exciton recombination inside $\mathrm{Si}$ ncs embedded in $\mathrm{SiO}_{2}$ or via $\mathrm{Si} / \mathrm{SiO}_{2}$ interface states and/or $\mathrm{SiO}_{2}$ host defects. Thus, we studied, at first, the effect of an annealing treatment on the Si-ncs formation to optimize the emitting properties of the materials for future superlattices. Then, the effect of $\mathrm{Nd}^{3+}$ doping on the optimized SRSO layers was investigated.

Figure 4a represents the PL spectra of the SRSO layers grown with different RFP-Si values and annealed at $1100{ }^{\circ} \mathrm{C}$
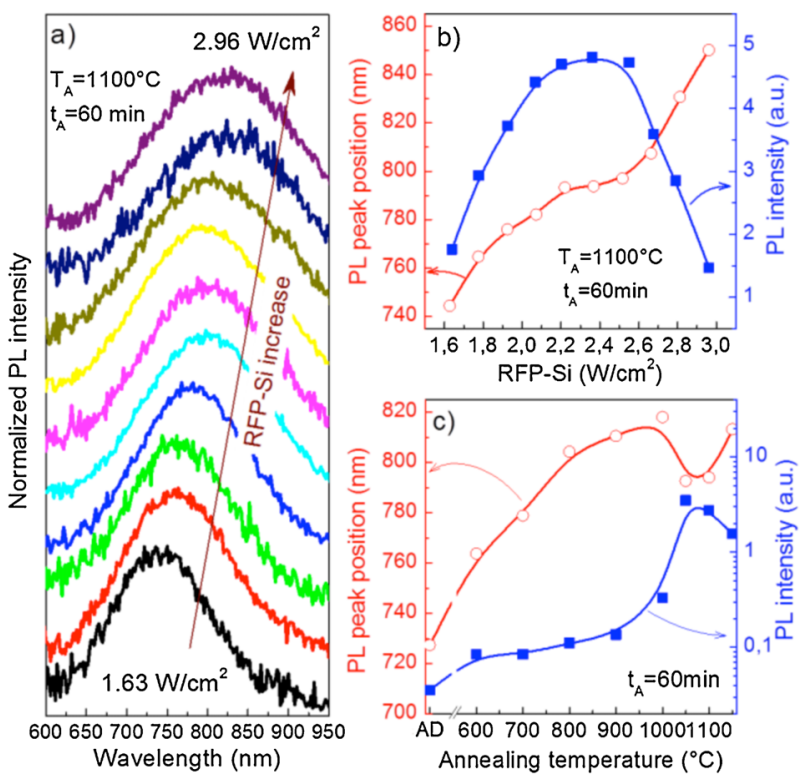

Figure 4 Effect of the RFP-Si on PL spectra (a), PL peak position and PL intensity (b) of SRSO single layers annealed at $1100{ }^{\circ} \mathrm{C}$ for 60 min. (c) Evolution of PL peak position and PL intensity with annealing temperature observed for the SRSO layer grown with $\mathrm{RFP}-\mathrm{Si}=2.36 \mathrm{~W} \mathrm{~cm}^{-2}$ showing the highest PL intensity. The data at "AD" corresponds to the PL parameters of as-deposited samples. Annealing time is $60 \mathrm{~min}$.

during $60 \mathrm{~min}$ in nitrogen flow. As one can see, the increase of Si content in SRSO layers (monitored by the RFP-Si value) favors a shift of the PL peak position from about $745 \mathrm{~nm}\left(x=1.72, \quad\right.$ RFP-Si $\left.=1.63 \mathrm{~W} \mathrm{~cm}^{-2}\right)$ to about $845 \mathrm{~nm}\left(x=1.49\right.$, RFP-Si $\left.=2.96 \mathrm{~W} \mathrm{~cm}^{-2}\right)$ as well as a peak broadening (Fig. 4a and b). This behavior of PL peak position is explained by the formation of Si-ncs with larger mean size and wider distribution when Si content increases.

The non-monotonous behavior of PL intensity can be caused by the increase of the number of Si-ncs when RFP-Si increases up to $2.2 \mathrm{~W} \mathrm{~cm}^{-2}$, whereas the PL quenching for RFP-Si $>2.5 \mathrm{~W} \mathrm{~cm}^{-2}$ is due to formation of larger Si-ncs and contribution of non-radiative channel (e.g., Si dangling bonds). The highest PL intensity was observed for the SRSO single layers with $x=1.5-1.6$ (grown with RFP-Si $=2.2$ $2.5 \mathrm{~W} \mathrm{~cm}^{-2}$ ).

The effect of different annealing treatments on PL properties was investigated for SRSO samples fabricated with different conditions, but hereafter the most efficient samples will be described. Thus, the increase of the annealing temperature, $T_{\mathrm{A}}$, up to $1000{ }^{\circ} \mathrm{C}$, enhances the PL intensity and favors the shift of its peak position from $730 \mathrm{~nm}$ (as-deposited sample) to $820 \mathrm{~nm}\left(T_{\mathrm{A}}=1000{ }^{\circ} \mathrm{C}\right.$; Fig. 4c). The comparison of these results with the evolution of $\mathrm{LO}_{3}$ and $\mathrm{TO}_{3}$ phonons obtained from FTIR data for the same sample (Fig. 3b) allows to explain this PL behavior by the formation of amorphous Si nuclei (or agglomerates) and their growing with $T_{\mathrm{A}}$. The sharp increase of PL intensity 
observed for samples annealed at $T_{\mathrm{A}}=1050-1100{ }^{\circ} \mathrm{C}$ (Fig. 3b) and the "blue" shift of PL peak position due to the crystallization of $\mathrm{Si}$ agglomerates accompanied by $\mathrm{Si} / \mathrm{SiO}_{2}$ interface shell formation. This latter provides the better confinement of the carriers inside Si-ncs leading to higher PL emission. Further $T_{\mathrm{A}}$ rise up to $1150{ }^{\circ} \mathrm{C}$ results in a PL quenching and a slight shift of the PL peak position to $810 \mathrm{~nm}$ (Fig. 4c). This shift can be due to the expansion of the Si-ncs via a coalescence of the smaller Si-ncs, whereas the PL intensity decrease can be explained by a significant contribution of non-radiative channels (e.g., Si dangling bonds formed at the $\mathrm{Si}-\mathrm{ncs} / \mathrm{SiO}_{2}$ host interface).

\subsection{Properties of $\mathrm{Nd}^{3+}$-doped single SRSO} layers Investigation of light emission from $\mathrm{Nd}^{3+}$-doped single SRSO layers was performed under excitation by $488 \mathrm{~nm}$ light wavelength. This is a non-resonant excitation of $\mathrm{Nd}^{3+}$ ions revealing an energy transfer from Si-ncs (or host-defects, if any) towards rare-earth ions. The intra-4f shell transitions of $\mathrm{Nd}^{3+}$ from the ${ }^{4} \mathrm{~F}_{3 / 2}$ level to the ${ }^{4} \mathrm{I}_{9 / 2}$ $(0.92 \mu \mathrm{m}),{ }^{4} \mathrm{I}_{11 / 2}(1.06 \mu \mathrm{m})$, and ${ }^{4} \mathrm{I}_{13 / 2}(1.35 \mu \mathrm{m})$ levels ions can be observed. Among them, $0.92 \mu \mathrm{m} \mathrm{Nd}^{3+} \mathrm{PL}$ transition cannot be excited via the bulk Si bandgap due to its lower energy. This particularity will be used to demonstrate an interaction between $\mathrm{Si}$-ncs and/or host defects with $\mathrm{Nd}^{3+}$ ions.

Figure $5 \mathrm{a}$ and $\mathrm{b}$ shows the PL emission of $\mathrm{Nd}^{3+}$-doped SRSO samples versus $T_{\mathrm{A}}$. As one can see, as-deposited samples (AD) demonstrate $\mathrm{Nd}^{3+}$ PL band (at $0.92 \mu \mathrm{m}$ ) under non-resonant excitation (Fig. 5). This gives an evidence of the interaction between $\mathrm{Nd}^{3+}$ ions and $\mathrm{Si}$ agglomerates formed during deposition process, similarly to the phenomena described in our previous works for $\mathrm{Er}^{3+}$-doped SRSO materials [47] and recently demonstrated for $\mathrm{Nd}^{3+}$-doped SRSO layers with lower Si content [33, 34].

The annealing treatment results in the activation of $\mathrm{Nd}^{3+}$ emission. However, the dependence of its PL intensity versus $T_{\mathrm{A}}$ has a non-monotonous behavior (Fig. 5c). The intense $\mathrm{Nd}^{3+}$ emission is observed for the samples annealed at $T_{\mathrm{A}}=600-800{ }^{\circ} \mathrm{C}$ and $1050-1100{ }^{\circ} \mathrm{C}$. In the first case, $T_{\mathrm{A}}=600-800{ }^{\circ} \mathrm{C}$, intense $\mathrm{Nd}^{3+}$ emission is due to an energy transfer from $\mathrm{Si}$ agglomerates. Their number decreases at $T_{\mathrm{A}}=900-1000{ }^{\circ} \mathrm{C}$ due to their coalescence that quenches $\mathrm{Nd}^{3+} \mathrm{PL}$ emission. Further $T_{\mathrm{A}}$ increase $\left(1050-1100{ }^{\circ} \mathrm{C}\right)$ leads to the appearance of "visible" PL emission (due to Si-ncs formation) that, as a consequence, enhances $\mathrm{Nd}^{3+}$ luminescence (Fig. 5b and c). The PL intensity in the visible spectral range is similar to that
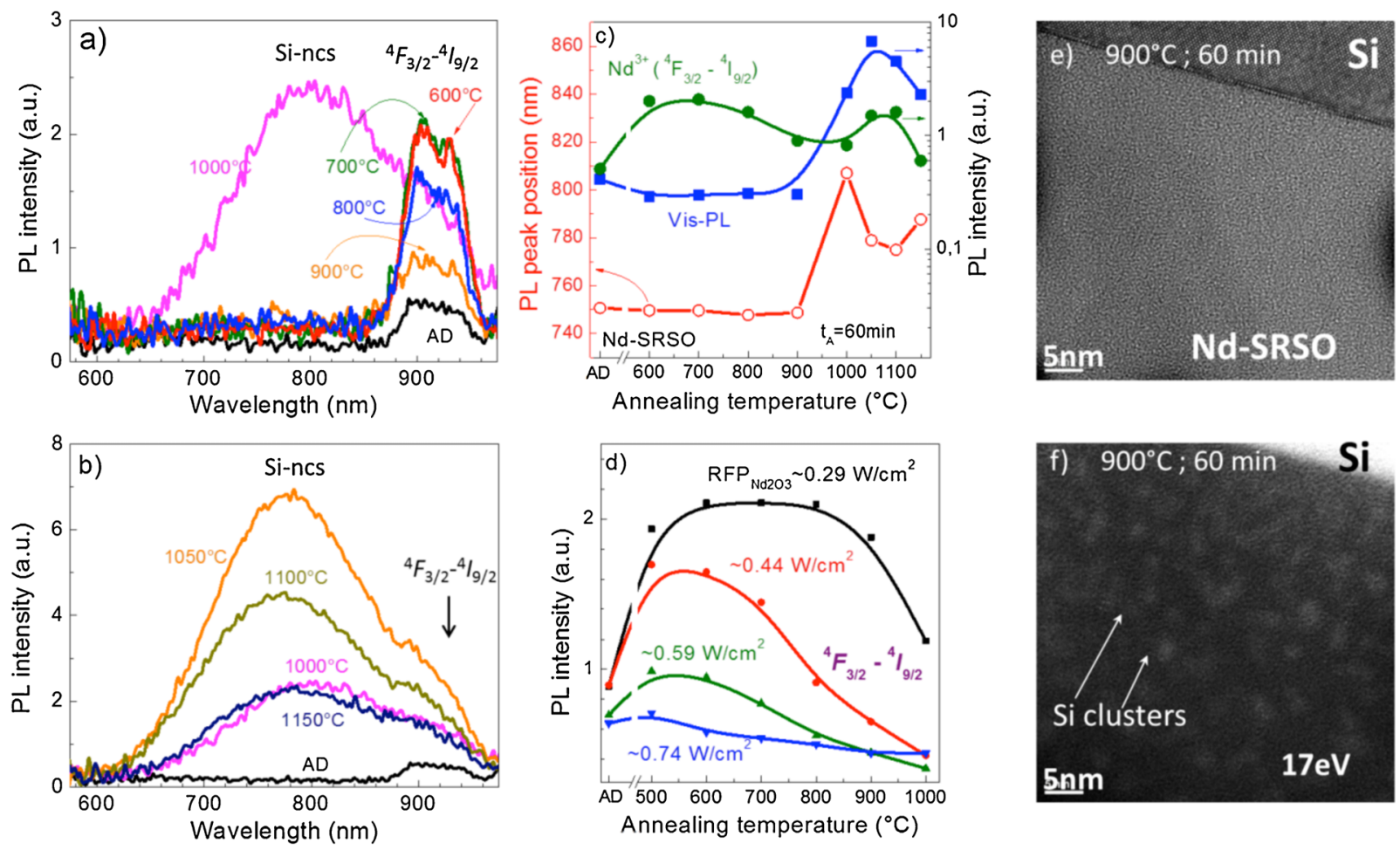

Figure 5 ( $\mathrm{a}$ and $\mathrm{b}$ ) Evolution of PL spectra of Nd-doped SRSO single layer versus $T_{\mathrm{A}}$. The spectra for as-deposited (AD) and annealed at $T_{\mathrm{A}}=1000{ }^{\circ} \mathrm{C}$ samples are presented in both figures for comparison. (c) Variation of the peak position of visible PL component (corresponding to Si-ncs emission) and its intensity as well as PL intensity of $\mathrm{Nd}^{3+}{ }^{4} \mathrm{~F}_{3 / 2}-{ }^{4} \mathrm{I}_{9 / 2}$ radiative transition with annealing temperature. (d) Dependence of the $\mathrm{Nd}^{3+} \mathrm{PL}$ intensity $\left({ }^{4} \mathrm{~F}_{3 / 2}{ }^{4} \mathrm{I}_{9 / 2}\right.$ transition) for the layers grown with $\mathrm{RFP}-\mathrm{Nd}_{2} \mathrm{O}_{3}=0.29-0.74 \mathrm{~W} \mathrm{~cm}{ }^{-2}$ on annealing temperature. (e and f) Energy-filtered at $0 \mathrm{eV}$ (e) and $17 \mathrm{eV}$ (f) TEM images of the sample annealed at $T_{\mathrm{A}}=900{ }^{\circ} \mathrm{C}$. For all the figures the RFP-Si $=2.36 \mathrm{~W} \mathrm{~cm}^{-2}$ and $t_{\mathrm{A}}=60 \mathrm{~min}$. 
described for undoped samples (Fig. 4c). This is an evidence of the sensitizing role of Si-ncs towards rare-earth ions (Fig. 5c).

At the same time, some difference between undoped and $\mathrm{Nd}^{3+}$-doped SRSO layers can be seen from the comparison of the samples annealed at lower temperatures. Indeed, for $T_{\mathrm{A}}=600-900{ }^{\circ} \mathrm{C}$, the peak position of the visible PL band is almost constant (about $750 \mathrm{~nm}$; Fig. 5c), as opposed to that observed for undoped materials (gradual shift from 750 to $810 \mathrm{~nm}$ (Fig. 4c)). The weak visible emission is accompanied by an intense $\mathrm{Nd}^{3+}$ PL with a slight decrease for $T_{\mathrm{A}}=900{ }^{\circ} \mathrm{C}$ (Fig. 5b). Since the formation of crystallized $\mathrm{Si}$ clusters is hardly believed upon such a treatment, one can assume an energy transfer from amorphous $\mathrm{Si}$ clusters towards $\mathrm{Nd}^{3+}$ ions. To confirm the presence of $\mathrm{Si}$ clusters (either amorphous or crystallized), these samples were investigated by TEM.

Thermal response of $\mathrm{Nd}^{3+} \mathrm{PL}$ emission was also investigated for samples with different rare-earth contents. Figure $5 \mathrm{~d}$ shows that high $\mathrm{Nd}^{3+}$ content leads to the quenching of $\mathrm{Nd}^{3+} \mathrm{PL}$ emission. However, the highest $\mathrm{Nd}^{3+}$ PL intensity for heavily doped samples can be achieved at lower $T_{\mathrm{A}}$. Thus, the most efficient $\mathrm{Nd}^{3+} \mathrm{PL}$ emission for samples grown with $\mathrm{RFP}-\mathrm{Nd}_{2} \mathrm{O}_{3}=0.29 \mathrm{~W} \mathrm{~cm}^{-2}$ ([Nd] $\leq 10^{20}$ at $\mathrm{cm}^{-3}$ ) was observed upon annealing treatment for $T_{\mathrm{A}}=600-800{ }^{\circ} \mathrm{C}$, whereas for the layers grown with higher RFP- $\mathrm{Nd}_{2} \mathrm{O}_{3}\left([\mathrm{Nd}] \geq 10^{21}\right.$ at cm ${ }^{-3}$ ), it was obtained with $T_{\mathrm{A}}=500-600{ }^{\circ} \mathrm{C}$ (Fig. 5d). This PL behavior of highly doped layers $\left([\mathrm{Nd}]>10^{21}\right.$ at $\mathrm{cm}^{-3}$ ) is explained by the higher probability of $\mathrm{Nd}^{3+}-\mathrm{Nd}^{3+}$ interaction processes as well as significant host distortion leading to the contribution of non-radiative channels. Besides, the segregation of $\mathrm{Nd}^{3+}$ ions has to be also considered as it was demonstrated by the FTIR data (Fig. 3d and e). Similar rare-earth clustering and formation of the $\mathrm{Nd}_{2} \mathrm{O}_{3}$ phase was also observed for $\mathrm{Nd}^{3+}$-doped SRSO materials with $[\mathrm{Nd}] \approx 2.8 \times 10^{21}$ at $\mathrm{cm}^{-3}$ (4.8 at\%) and $x=1.8$, fabricated by reactive magnetron sputtering [31].

Taking into account these results, one can conclude that our $\mathrm{Nd}^{3+}$-doped SRSO samples have an optimal $\mathrm{Nd}^{3+}$ content lower than $10^{21}$ at $\mathrm{cm}^{-3}$. Thus, $\mathrm{RFP}-\mathrm{Nd}_{2} \mathrm{O}_{3}=$ $0.29 \mathrm{~W} \mathrm{~cm}^{-2}$ was used for the fabrication of $\mathrm{Nd}^{3+}$-doped structures along with the other conditions described in Table 1. They allow the achievement of bright $\mathrm{Nd}^{3+}$ emission not only for samples annealed at high $T_{\mathrm{A}}$, but also for as-deposited layers and those submitted to thermal treatments at moderate temperatures $\left(600-800{ }^{\circ} \mathrm{C}\right)$. In this case, the efficient excitation of $\mathrm{Nd}^{3+}$ ions is due to energy transfer from Si agglomerates. To confirm their presence (either amorphous or crystallized) for the samples annealed at moderate temperatures, the Nd-doped layers treated at $T_{\mathrm{A}}=900{ }^{\circ} \mathrm{C}$ for $60 \mathrm{~min}$ in nitrogen flow were investigated by TEM method.

Zero-loss energy-filtered TEM observation of Nd-doped sample annealed at $T_{\mathrm{A}}=900{ }^{\circ} \mathrm{C}$ for $60 \mathrm{~min}$ in nitrogen flow did not reveal any formation of crystallized grains (either $\mathrm{Si}-$ ncs or Nd-related ones; Fig. 5e). This means that the samples remain amorphous upon annealing at $T_{\mathrm{A}} \leq 900{ }^{\circ} \mathrm{C}$. To reveal the presence of $\mathrm{Si}$ clusters, energy filtered TEM observations at $17 \mathrm{eV}$, corresponding to Si plasmon energy, were performed for the same sample. As shown in Fig. 5f, numerous amorphous Si-ncs were found in the samples. These results along with PL data confirm the sensitizing role of amorphous $\mathrm{Si}$ clusters towards rare-earth ions for the samples upon low-temperature annealing treatments $\left(T_{\mathrm{A}} \leq 900{ }^{\circ} \mathrm{C}\right)$.

\subsection{Properties of undoped and Nd-doped SRSO/} $\mathrm{SiO}_{2}$ superlattices Taking into account the results described above for single layers, we fabricated superlattices using the optimal deposition conditions $\left(\mathrm{RFP}-\mathrm{SiO}_{2}=\right.$ $8.88 \mathrm{~W} \mathrm{~cm}^{-2}$ and RFP-Si $=2.36 \mathrm{~W} \mathrm{~cm}^{-2}$ as well as RFP- $\mathrm{Nd}_{2} \mathrm{O}_{3}=0.29 \mathrm{~W} \mathrm{~cm}^{-2}$ (for $\mathrm{Nd}^{3+}$ doped sublayers)). The SRSO sublayer thickness was fixed at $3 \mathrm{~nm}$ (as for undoped and doped sublayers), whereas that of $\mathrm{SiO}_{2}$ sublayers was tuned in the $1.5-5.0 \mathrm{~nm}$ range. Considering the similar Si excess content in the SRSO sublayers, the annealing treatment at $T_{\mathrm{A}}=1100{ }^{\circ} \mathrm{C}$ can lead to the formation of Si-ncs with similar size distributions.

The investigation of PL properties of undoped superlattices annealed at $T_{\mathrm{A}}=1100{ }^{\circ} \mathrm{C}$ revealed a blue shift of PL peak position of the Si-ncs from about $745 \mathrm{~nm}(1.5 \mathrm{~nm}$ $\left.\mathrm{SiO}_{2}\right)$ via $733 \mathrm{~nm}\left(2.5 \mathrm{~nm} \mathrm{SiO}_{2}\right)$ down to $730 \mathrm{~nm}(3.8 \mathrm{~nm}$ $\mathrm{SiO}_{2}$; not shown here). This "blue" shift was accompanied by an increase of the PL intensity in one order of magnitude. It was explained by the fact that thinner $\mathrm{SiO}_{2}$ barriers cannot efficiently confine the $\mathrm{Si}$ atoms in SRSO layers and, thus, Si out-diffusion can occur. This favors Sincs formation with larger sizes (i.e., exceeding SRSO layer thickness). Thicker $\mathrm{SiO}_{2}$ barriers favor the physical confinement of Si atoms in SRSO sublayers as well as a better confinement of the carriers in the Si-ncs formed. This latter stimulates an enhancement of their PL intensity. It is worth to note that further increase of $\mathrm{SiO}_{2}$ thickness (up to $5 \mathrm{~nm}$ ) did not lead to a shift of PL peak position of Si-ncs. However, in terms of future application of $\mathrm{SRSO} / \mathrm{SiO}_{2}$ superlattices, thicker $\mathrm{SiO}_{2}$ sublayers are undesirable due to higher resistivity of the whole structure [48]. Thus, hereafter, the properties of undoped and Nd-doped SRSO/ $\mathrm{SiO}_{2}$ superlaticces with $3 \mathrm{~nm}-\mathrm{SRSO}$ and $3 \mathrm{~nm} \mathrm{SiO}{ }_{2}$ sublayers will be described.

Figure 6 shows the PL properties of superlattices versus annealing treatment. As one can see, an increase of the annealing temperature from 600 to $900{ }^{\circ} \mathrm{C}$ does not affect the PL peak position $(760 \mathrm{~nm})$, but it results in an increase of PL intensity. Further $T_{\mathrm{A}}$ rise stimulates an enhancement of PL emission up to some saturation $\left(T_{\mathrm{A}}=1100-1150{ }^{\circ} \mathrm{C}\right.$; Fig. 6a and b). Comparison between this PL behavior with that observed for single SRSO layer (Fig. 4c) shows that the formation of Si-ncs in the superlattices requires higher annealing temperatures. The highest PL intensity of single SRSO layer was achieved at $1050-1100{ }^{\circ} \mathrm{C}$, while for $\mathrm{SRSO} / \mathrm{SiO}_{2}$ superlattice, the most efficient emission is observed after annealing at $1100-1150{ }^{\circ} \mathrm{C}$. 

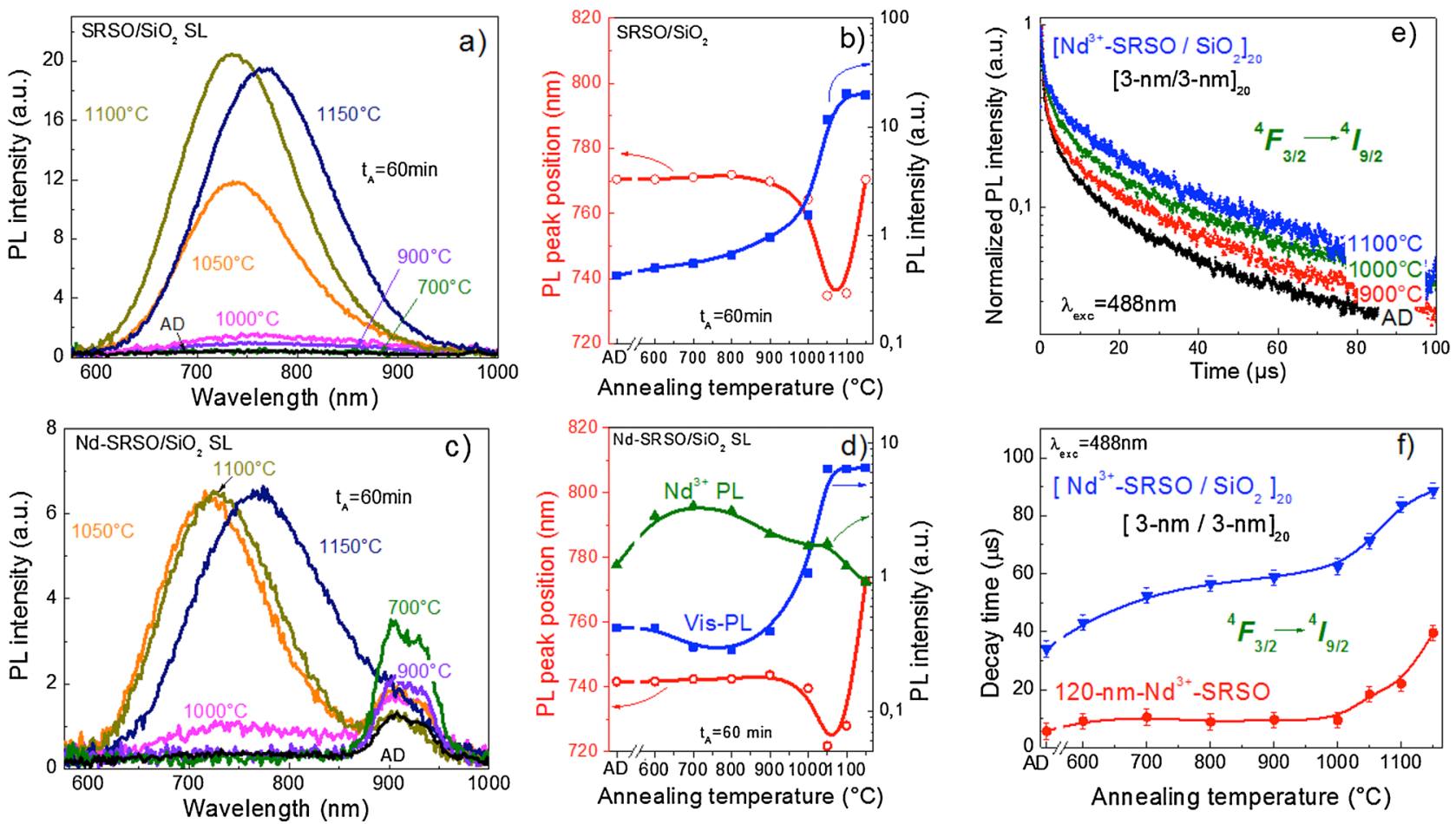

Figure 6 PL properties evolution of undoped ( $a$ and b) and Nd-doped (c-e) SRSO/SiO $/ 2$ superlattices for different annealing temperatures; $t_{\mathrm{A}}=60 \mathrm{~min}$. Parts (e) and (f) represent the effect of annealing temperature on the $\mathrm{Nd}^{3+} \mathrm{PL}$ life-time for the ${ }^{4} \mathrm{~F}_{3 / 2}{ }^{4} \mathrm{I}_{9 / 2}$ radiative transition $(0.92 \mu \mathrm{m})$ obtained for $\mathrm{Nd}^{3+}$-doped SRSO single layer and $\mathrm{Nd}^{3+}-\mathrm{SRSO} / \mathrm{SiO}_{2}$ superlattices.

Similar results were observed in Ref. [17] and explained by the appearance of strain field at the $\mathrm{SRSO} / \mathrm{SiO}_{2}$ interfaces impeding a lateral diffusion of $\mathrm{Si}$ atoms in the SRSO sublayers. This allows supposing an amorphous nature of the Si-ncs in $\mathrm{SRSO} / \mathrm{SiO}_{2}$ superlattices upon annealing at $T_{\mathrm{A}} \leq 900{ }^{\circ} \mathrm{C}$, whereas annealing at $1100-1150{ }^{\circ} \mathrm{C}$ favors $\mathrm{Si}$-ncs crystallization. This thermal behavior of $\mathrm{SRSO} / \mathrm{SiO}_{2}$ can also influence the $\mathrm{Nd}^{3+}$ emission.

The analysis of PL spectra of undoped and $\mathrm{Nd}^{3+}$-doped superlattices revealed similarities in the behavior of the peak positions of visible PL bands with $T_{\mathrm{A}}$ (Fig. $6 \mathrm{~b}$ and d). However, we observed about $30 \mathrm{~nm}$ "blue" shift of the PL peak position for doped samples annealed at $T_{\mathrm{A}}=500$ $1100{ }^{\circ} \mathrm{C}$ (Fig. 6d). This "artificial" shift is due to the energy transfer from the larger $\mathrm{Si}$ clusters towards $\mathrm{Nd}^{3+}$ ions. Indeed, when this transfer is not efficient $\left(T_{\mathrm{A}}=1150{ }^{\circ} \mathrm{C}\right)$, both (undoped and doped) superlattices have the same PL peak position at about $770 \mathrm{~nm}$ (Fig. 6b and d). This is confirmed by the similar thicknesses and Si excess of SRSO sublayers in both (un)doped superlattices because the Si-ncs size distribution has to be similar.

The brightest $\mathrm{Nd}^{3+}$ emission is achieved for moderate annealing temperatures $\left(T_{\mathrm{A}}=600-800{ }^{\circ} \mathrm{C}\right.$; Fig. $6 \mathrm{c}$ and d $)$. It is accompanied by the quenching of the visible emission from SRSO layers similarly to the case of Nd-doped SRSO single layers (Fig. 5). This correlation between PL intensity from Si-ncs and $\mathrm{Nd}^{3+}$ emission demonstrates the role of amorphous Si-ncs as effective sensitizers of rare-earth ions.
Further $T_{\mathrm{A}}$ increase results in a higher Si-ncs PL intensity and a simultaneous quenching of $\mathrm{Nd}^{3+}$ emission (Fig. $6 \mathrm{c}$ and d). In spite of the increase of Si-ncs density, this quenching can be due to either the formation of $\mathrm{Nd}$ clusters or more likely the increase of the Nd-Si-ncs interaction distance. Since our single Nd-doped SRSO samples have [Nd] $\approx 10^{20}$ at $\mathrm{cm}^{-3}$ and no evidence of the Nd clustering has been found, we can conclude that the $\mathrm{Nd}^{3+}$ PL quenching is due to an increase of Si-ncs- $\mathrm{Nd}^{3+}$ interaction distance.

The benefits of the superlattice approach can be seen from the comparison of the $\mathrm{Nd}^{3+} \mathrm{PL}$ decay time obtained for Nd-doped SRSO single layer and $\mathrm{Nd}-\mathrm{SRSO} / \mathrm{SiO}_{2}$ superlattice (Fig. 6e and f). This latter demonstrates higher $\mathrm{Nd}^{3+}$ life time (about $60 \mu \mathrm{s}$ for $T_{\mathrm{A}}=700-900{ }^{\circ} \mathrm{C}$ ) in comparison with that observed for single layer approach (about $15 \mu \mathrm{s}$ ). The shorter life-time in the last case can be due to the high $\mathrm{Si}$ excess content. Similar effect was observed for the $\mathrm{Er}^{3+}$ doped SRSO layers grown with the same approach [47]. Both single layer and superlattices demonstrate an increase of the life-time with $T_{\mathrm{A}}$ (Fig. 6e and f), whereas the total intensity of $\mathrm{Nd}^{3+}$ PL emission decreases (Fig. $6 \mathrm{~b}$ and d). The life-time increase is due to an improvement of the $\mathrm{Nd}^{3+}$ environment (via a recovering of $\mathrm{Si}-\mathrm{O}$ bond angle towards that of $\mathrm{SiO}_{2}$ host (Fig. 3)), whereas the PL quenching is caused by the Si-ncs number decrease (due to their sizes' increase) and by the increase of the Si-ncs-Nd ${ }^{3+}$ interaction distance. Besides, the $\mathrm{Nd}^{3+}$ clustering can also affect PL properties. However, in the case of superlattice structures, 
this effect is much less pronounced that is evidenced by the higher $\mathrm{Nd}^{3+}$ PL life-time (Fig. 6f).

We carried out TEM observations for the investigation of the Si-ncs formation in our superlattices. The bright and dark field images are presented in Fig. 7. As one can see, both annealed samples conserve the periodicity of the structures. However, the sample annealed at $T_{\mathrm{A}}=700{ }^{\circ} \mathrm{C}$ during $60 \mathrm{~min}$ is still amorphous; no formation of crystallized Si-ncs was revealed. Annealing at $1100{ }^{\circ} \mathrm{C}$ during $60 \mathrm{~min}$ showed the presence of numerous crystallized Si-ncs, confined in the SRSO sublayers.

Note that in this case, any $\mathrm{Nd}^{3+}$-rich cluster with a size larger than $2 \mathrm{~nm}$ was not seen. Meanwhile, this cannot allow us to conclude definitely about either their presence or absence in the samples. It is known that rare-earth ions have an ability for clustering in $\mathrm{SiO}_{2}$-based hosts and this is more likely for low atomic numbers of lanthanide ions [49, 50]. We could then suppose the presence of such $\mathrm{Nd}^{3+}$-rich small clusters in our samples containing about $[\mathrm{Nd}] \approx 10^{20}$ at $\mathrm{cm}^{-3}$ similarly to the case described for $\mathrm{Er}^{3+}$-doped SRSO single layers grown by the same sputtering approach and annealed at $1100{ }^{\circ} \mathrm{C}$ [51]. We observed that about $30 \%$ of the total $\mathrm{Er}^{3+}$ amount form these clusters leading to the quenching of their emitting activity. A similar investigation

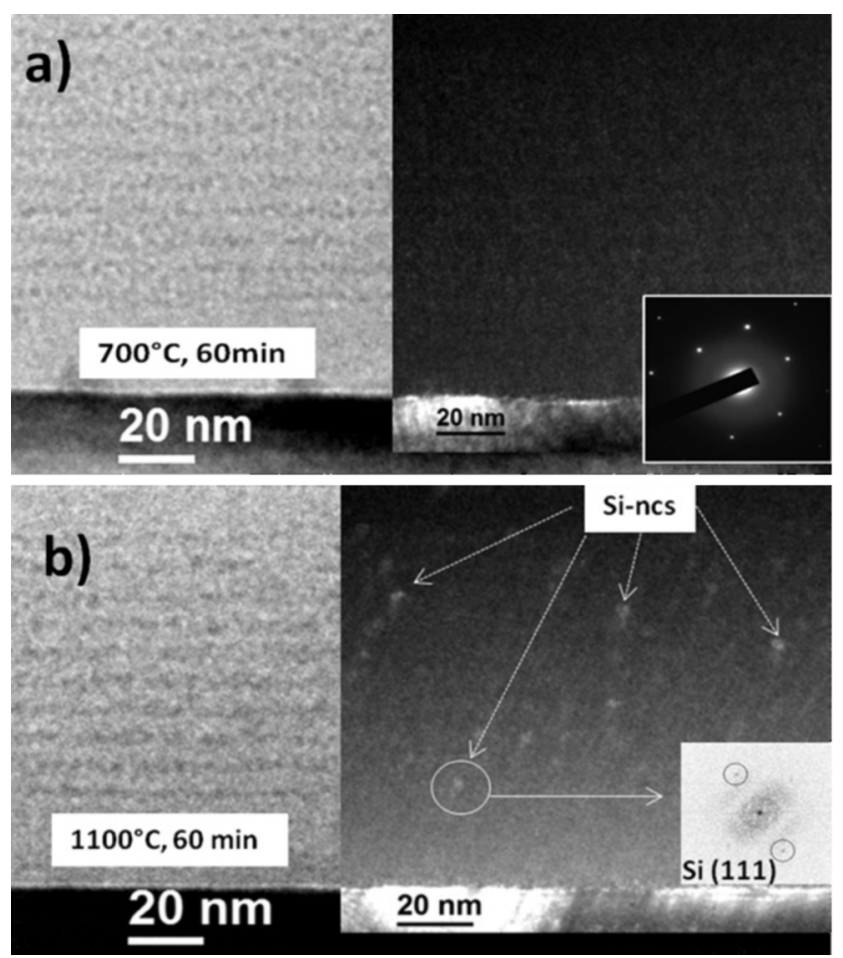

Figure 7 Bright and dark field TEM images of $\mathrm{Nd}-\mathrm{SRSO} / \mathrm{SiO}_{2}$ superlattice annealed at $T_{\mathrm{A}}=700{ }^{\circ} \mathrm{C}$ (a) and $1100{ }^{\circ} \mathrm{C}$ (b) for $60 \mathrm{~min}$ in nitrogen flow. The inset in (a) is a selected area electron diffraction (SAED) image confirming the amorphous nature of the sample. The inset in (b) is a filtered Fourier transform (FFT) image from a bright spot (marked as a ring) showing the (111) Si planes and thus, the formation of crystallized Si-ncs. of Nd-doped SRSO samples with different $\mathrm{Nd}$ contents described above by the atom probe technique is in progress.

The results described above demonstrate that Si-ncs (either amorphous or crystallized) are effective sensitizers of rare-earth ions. Earlier, we showed that some host defects such as Si-oxygen deficient centers (Si-ODC), can effectively transfer energy towards $\mathrm{Er}^{3+}$ ions $[28,52]$ under high energy excitation (X-ray or ultraviolet-blue excitation). Similar data were obtained for $\mathrm{Nd}^{3+}$-doped SRSO layers demonstrating efficient short-wavelength excitation of $\mathrm{Nd}^{3+}$ ions. Although in all our study we used 488-nm excitation light, we cannot rule out the presence of some host defects in our samples able to contribute to the $\mathrm{Nd}^{3+}$ excitation process. To investigate the role of the defects of $\mathrm{SiO}_{2}$ host on $\mathrm{Nd}^{3+} \mathrm{PL}$ emission, along with $\mathrm{Nd}-\mathrm{SRSO} / \mathrm{SiO}_{2}$ superlattices, we fabricated structures, where either both sublayers or only $\mathrm{SiO}_{2}$ barriers were $\mathrm{Nd}^{3+}$-doped and studied the annealing treatment effect on PL properties of the structures.

\subsection{Effect of sublayers' doping on PL properties} of superlattices As shown above, among the different key parameters governing the optical properties of superlattices, the thickness of each type of sublayers plays an important role. Along with this, the location of rare-earth ions (either in $\mathrm{SRSO}$ or $\mathrm{SiO}_{2}$ only, or in both sublayers simultaneous) also has to be considered. Thus, besides the $\mathrm{Nd}-\mathrm{SRSO} / \mathrm{SiO}_{2}$ superlattices, the $\mathrm{Nd}-\mathrm{SRSO} / \mathrm{Nd}-\mathrm{SiO}_{2}$ and $\mathrm{SRSO} / \mathrm{Nd}-\mathrm{SiO}_{2}$ samples were fabricated. Thermal treatments were performed at different temperatures (600-1150 $\left.{ }^{\circ} \mathrm{C}\right)$. However, Fig. 8 shows PL spectra for two specific annealing regimes, $700{ }^{\circ} \mathrm{C}$ (the most intense emission from $\mathrm{Nd}^{3+}$ ions) and $1100{ }^{\circ} \mathrm{C}$ (the highest Si-ncs emission). An annealing at $1100{ }^{\circ} \mathrm{C}$ results in a visible emission. Its PL peak position is almost constant for all three sets of samples that is an evidence of similar Si-ncs distribution in the structures (Fig. 8). The highest visible PL intensity is observed for

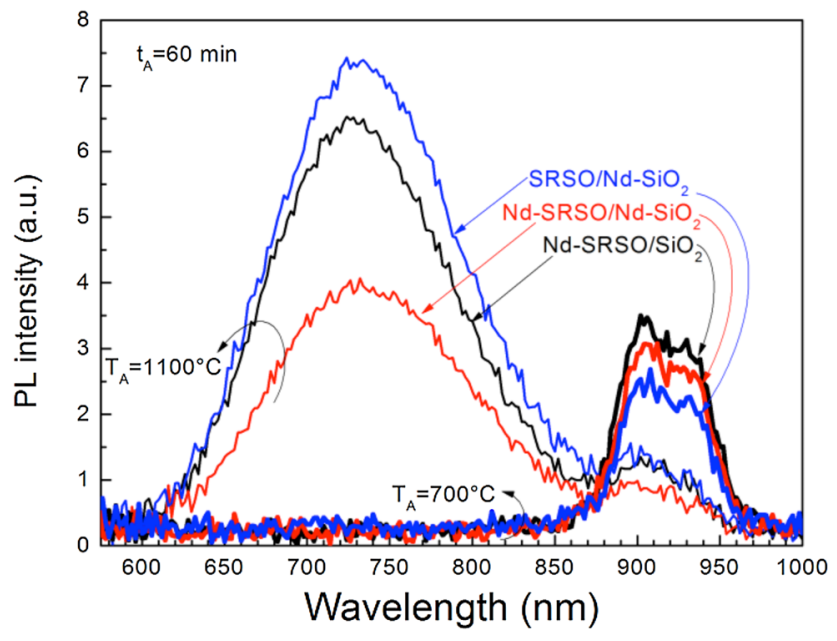

Figure $8 \mathrm{PL}$ spectra of $\mathrm{SRSO} / \mathrm{SiO}_{2}$ superlattices partly or fully doped with $\mathrm{Nd}^{3+}$ ions. Annealing temperatures were 700 and $1100{ }^{\circ} \mathrm{C}$. 
$\mathrm{SRSO} / \mathrm{Nd}-\mathrm{SiO}_{2}$ structures, whereas the lowest value is obtained for fully doped superlattices (Fig. 8).

Since TEM data confirmed the formation of Si-ncs in the SRSO layers (Fig. 7b), this PL behavior from different superlattices can be explained by the fact that for $\mathrm{SRSO} / \mathrm{Nd}-\mathrm{SiO}_{2}$ samples, only $\mathrm{Si}$-ncs close to $\mathrm{SRSO} / \mathrm{SiO}_{2}$ interface can participate to the excitation of $\mathrm{Nd}^{3+}$ ions. This results in a slight quenching of own Si-ncs emission. In the case of $\mathrm{Nd}-\mathrm{SRSO} / \mathrm{SiO}_{2}$ and $\mathrm{Nd}-\mathrm{SRSO} / \mathrm{Nd}-\mathrm{SiO}_{2}$ the Si-ncs act as sensitizers of $\mathrm{Nd}^{3+}$ ions located either in SRSO or both $\mathrm{SRSO}$ and $\mathrm{SiO}_{2}$ sublayers, being, in the last case, very close to the $\mathrm{SRSO} / \mathrm{SiO}_{2}$ interface. The analysis of the PL intensities shows comparable Si-ncs PL amplitudes for $\mathrm{SRSO} / \mathrm{Nd}-\mathrm{SiO}_{2}$ and $\mathrm{Nd}-\mathrm{SRSO} / \mathrm{SiO}_{2}$ structures whereas for the fully doped structure, PL of Si-ncs has twice less intensity. This is an additional argument for the Si-ncs interaction with the $\mathrm{Nd}^{3+}$ ions located in a vicinity of the $\mathrm{SRSO} / \mathrm{SiO}_{2}$ interfaces. Another argument of the Si-ncs quenching could be a formation of some Nd-rich clusters that can act as non-radiative channels.

The most efficient $\mathrm{Nd}^{3+}$ emission was achieved for Nd$\mathrm{SRSO} / \mathrm{SiO}_{2}$ structures (Fig. 8). Its quenching with $T_{\mathrm{A}}$ can be due to a mismatching between the $\mathrm{Nd}^{3+}$ levels and the Si-ncs bandgap, governed by higher annealing temperature as it was shown in Ref. [53] for Nd-doped SRSO samples. Although, in most cases, the excitation mechanism of $\mathrm{Nd}^{3+}$ ions is considered to be similar to the Si-ncs-Er ${ }^{3+}$ interaction, the different nature of $\mathrm{Nd}^{3+}$ ions requires more investigation to reveal the ways of their efficient excitation.

The highest $\mathrm{Nd}^{3+}$ emission for $\mathrm{Nd}-\mathrm{SRSO} / \mathrm{SiO}_{2}$ superlattices was obtained upon annealing at $700{ }^{\circ} \mathrm{C}$. However, a comparable $\mathrm{Nd}^{3+}$ intensity was also deteced for Nd-SRSO/ $\mathrm{Nd}-\mathrm{SiO}_{2}$ (Fig. 8). Thus, based on the assumption that amorphous Si agglomerates (or nanoclusters), formed in the SRSO layers at $T_{\mathrm{A}}=700{ }^{\circ} \mathrm{C}$, can act as efficient sensitizers of $\mathrm{Nd}^{3+}$ ions, we have to assume that the energy transfer occurs from Si-ncs towards $\mathrm{Nd}^{3+}$ ions not only for the ions located in the Nd-SRSO sublayers, but also in the vicinity of the $\mathrm{Nd}-\mathrm{SRSO} / \mathrm{Nd}-\mathrm{SiO}_{2}$ interfaces. However, this assumption cannot only be a reason for this intense PL emission, because an efficient $\mathrm{Nd}^{3+} \mathrm{PL}$ was found for SRSO/Nd-SiO structures, where only $\mathrm{SiO}_{2}$ sublayers were doped with $\mathrm{Nd}^{3+}$ ions. Thus, in this case, we have to assume: (i) either a contribution of additional excitation channel for $\mathrm{Nd}^{3+}$ ions. This latter can be some host defects (for instance, Si-ODC) that can interact with $\mathrm{Si}$-ncs and $\mathrm{Nd}^{3+}$ ions similar to the case described for $\mathrm{Er}^{3+}$-doped SRSO materials [52]; (ii) or the possibility for $\mathrm{Nd}^{3+}$ ions to diffuse towards $\mathrm{SRSO} / \mathrm{SiO}_{2}$ interfaces. Since $\mathrm{SRSO}$ and $\mathrm{SiO}_{2}$ materials have different lattice parameters and SRSO is usually stressed, the appearance of the strain field at the $\mathrm{SRSO} / \mathrm{SiO}_{2}$ interfaces in the superlattices can be a driving force for $\mathrm{Nd}^{3+}$ diffusion towards the interfaces. However, this issue needs further investigation.

It is worth to note that an effect of other alternated sublayers on the $\mathrm{Nd}^{3+}$ emission is the matter of future work. Recently, a lot of studies have been focused on Si nitrides or oxynitrides because of their potential use as alternating barrier materials $[3,54,55]$. They offer a better conductivity in comparison with $\mathrm{SiO}_{2}$ barriers [48] as well as a promising optical activity of $\mathrm{Nd}^{3+}$ ions [56]. However, the mechanism of their excitation is still debatable and requires deeper investigations for effective control of rare-earth emission.

4 Conclusions This work presents the benefits of the superlattice approach to control microstructure and light emission properties of Si nanoclusters and rare-earth ions. The post-fabrication processing showed that the formation of Si-ncs in $\mathrm{SRSO} / \mathrm{SiO}_{2}$ superlattices occurs at higher annealing temperatures than in single SRSO layers. The efficient $\mathrm{Nd}^{3+}$ emission was achieved at moderate annealing temperatures $\left(600-800{ }^{\circ} \mathrm{C}\right)$. It was demonstrated that amorphous Si nanoclusters are efficient sensitizers of rareearth ions.

Acknowledgements This work was supported by the French National Research Agency (ANR) through Nanoscience and Nanotechnology Program (DAPHNES project ANR-08NANO-005). Authors would like to thank Dr. J. Perrière from Institut des NanoSciences de Paris (INSP/CNRS, Paris) for RBS measurements.

\section{References}

[1] L. T. Canham, Appl. Phys. Lett. 57, 1046 (1990).

[2] V. Lehmann and U. Gösele, Appl. Phys. Lett. 58, 856 (1991).

[3] G. Conibeer, M. Green, E.-Ch. Cho, D. König, Y.-H. Cho, T. Fangsuwannarak, G. Scardera, E. Pink, Y. Huang, T. Puzzer, S. Huang, D. Song, C. Flynn, S. Park, X. Hao, and D. Mansfield, Thin Solid Films 516, 6748 (2008).

[4] D. J. Lockwood, Z. H. Lu, and J. M. Baribeau, Phys. Rev. Lett. 76, 539 (1996).

[5] M. Zacharias, J. Heitmann, R. Scholz, U. Kahler, M. Schmidt, and J. Bläsing, Appl. Phys. Lett. 80, 661 (2002).

[6] C. L. Heng, B. R. Zhang, Y. P. Qiao, Z. C. Ma, W. H. Zong, and G. G. Qin, Physica B 270, 104 (1999).

[7] B. Berghoff, S. Suckow, R. Rölver, B. Spangenberg, H. Kurz, A. Sologubenko, and J. Mayer, J. Appl. Phys. 106, 083706 (2009).

[8] K. S. Min, K. V. Shcheglov, C. M. Yang, H. A. Atwater, M. L. Brongersma, and A. Polman, Appl. Phys. Lett. 69, 2033 (1996).

[9] D. Li, Y.-B. Chen, Y. Ren, J. Zhu, Y.-Y. Zhao, and M. Lu, Nanoscale Res. Lett. 7, 200 (2012).

[10] U. Kahler and H. Hofmeister, Opt. Mater. 17, 83 (2001).

[11] J. Heitmann, R. Scholz, M. Schmidt, and M. Zacharias, J. Non-Cryst. Solids 299-302, 1075 (2002).

[12] Z. X. Ma, X. B. Liao, J. He, W. C. Cheng, G. Z. Yue, Y. Q. Wang, and G. L. Kong, J. Appl. Phys. 83, 7934 (1998).

[13] C. Ternon, F. Gourbilleau, X. Portier, P. Voivenel, and C. Dufour, Thin Solid Films 419, 5 (2002).

[14] S. Y. Ma, Thin Solid Films 402, 222 (2002).

[15] S. Hayashi and K. Yamamoto, J. Lumin. 70, 352 (1996).

[16] L. Khomenkova, N. Korsunska, V. Yukhimchuk, B. Jumayev, T. Torchynska, A. Vivas Hernandez, A. Many, Y. Goldstein, E. Savir, and J. Jedrzejewski, J. Lumin. 102, 705 (2003). 
[17] T. Zheng and Z. Li, Superlattices Microstruct. 37, 227 (2005).

[18] M. Roussel, E. Talbot, F. Gourbilleau, and P. Pareige, Nanoscale Res. Lett. 6, 164 (2011).

[19] A. J. Kenyon, Semicond. Sci. Technol. 20, R65 (2005).

[20] S. Cueff, C. Labbé, O. Jambois, B. Garrido, X. Portier, and R. Rizk, Nanoscale Res. Lett. 6, 395 (2011).

[21] M. Wojdak, M. Klik, M. Forcales, O. B. Gusev, T. Gregorkiewicz, D. Pacifici, G. Franzò, F. Priolo, and F. Iacona, Phys. Rev. B 69, 233315 (2004).

[22] O. Jambois, F. Gourbilleau, A. J. Kenyon, J. Montserrat, R. Rizk, and B. Garrido, Opt. Express 18, 2230 (2010).

[23] J. Miniscalco, J. Lightwave Technol. 9, 234 (1991).

[24] S. Cueff, C. Labbé, J. Cardin, J.-L. Doualan, L. Khomenkova, K. Hijazi, O. Jambois, B. Garrido, and R. Rizk, J. Appl. Phys. 108, 064302 (2010).

[25] A. Podhorodecki, J. Misiewicz, F. Gourbilleau, J. Cardin, and C. Dufour, Electrochem. Solid-State Lett. 13(3), K26 (2010).

[26] J. M. Khoshman, A. Khan, and M. E. Kordesch, Surf. Coat. Technol. 202, 2500 (2008).

[27] O. Stenzel, S. Wilbrandt, S. Yulin, N. Kaiser, M. Held, A. Tünnermann, J. Biskupek, and U. Kaiser, Opt. Mater. Express 1, 278 (2011).

[28] M. Schmidt, M. Zacharias, S. Richter, P. Fischer, P. Veit, J. Bläsing, and B. Breeger, Thin Solid Films 397, 211 (2001).

[29] F. Gourbilleau, R. Madelon, C. Dufour, and R. Rizk, Opt. Mater. 27, 868 (2005).

[30] K. Watanabe, H. Tamaoka, M. Fujii, K. Moriwaki, and Sh. Hayashi, Physica E 13, 1038 (2002).

[31] O. Debieu, D. Bréard, A. Podhorodecki, G. Zatryb, J. Misiewicz, C. Labbé, J. Cardin, and F. Gourbilleau, J. Appl. Phys. 108, 113114 (2010).

[32] J. H. Campbell and T. I. Suratwala, J. Non-Cryst. Solids 263264, 318 (2000).

[33] F. Gourbilleau, D. Bréard, C. Dufour, and R. Rizk, Opt. Mater. 31, 479 (2009).

[34] C.-H. Liang, O. Debieu, Y.-T. An, L. Khomenkova, J. Cardin, and F. Gourbilleau, J. Lumin. 132, 3118 (2012).

[35] L. Khomenkova, C. Dufour, P.-E. Coulon, C. Bonafos, and F. Gourbilleau, Nanotechnology 21, 095704 (2010).
[36] http://www.horiba.com.

[37] E. Dehan, P. Temple-Boyer, R. Henda, J. J. Pedroviejo, and E. Scheid, Thin Solid Films 266, 14 (1995).

[38] C. T. Kirk, Phys. Rev. B 38, 1255 (1988).

[39] P. Lange, J. Appl. Phys. 66, 201 (1989).

[40] P. Innocenzi, J. Non-Cryst. Solids 316, 309 (2003).

[41] H. Ono, T. Ikarashi, K. Ando, and T. Kitano, J. Appl. Phys. 84, 6064 (1998).

[42] J. E. Olsen and F. Shimura, J. Appl. Phys. 66, 1353 (1989).

[43] D. V. Tsu, G. Lucovsky, and B. N. Davidson, Phys. Rev. B 40, 1795 (1989).

[44] M. G. Tucker, D. A. Keen, M. T. Dove, and K. Trachenko, J. Phys.: Condens. Matter 17, S67 (2005).

[45] P. G. Pai, S. S. Chao, Y. Takagi, and G. Lukovsky, J. Vac. Sci. Technol. A 4, 689 (1986).

[46] F. Gourbilleau, L. Khomenkova, D. Bréard, C. Dufour, and R. Rizk, Physica E 41, 1034 (2008).

[47] K. Hijazi, R. Rizk, J. Cardin, L. Khomenkova, and F. Gourbilleau, J. Appl. Phys. 106, 024311 (2009).

[48] R. Pratibha Nalini, P. Marie, J. Cardin, C. Dufour, P. Dimitrakis, P. Normand, M. Carrada, and F. Gourbilleau, Energy Proc. 10, 161 (2011).

[49] F. Rocca, C. Armellini, M. Ferrare, G. Dalba, N. Diab, A. Kuzmin, and F. Monti, J. Sol-Gel Sci. Technol. 26, 267 (2003).

[50] S. Sen and J. F. Stebbins, J. Non-Cryst. Solids 188, 54 (1995).

[51] E. Talbot, R. Lardé, P. Pareige, L. Khomenkova, K. Hijazi, and F. Gourbilleau, Nanoscale Res. Lett. 8, 39 (2013).

[52] S. Cueff, C. Labbé, B. Dierre, F. Fabbri, T. Sekiguchi, X. Portier, and R. Rizk, J. Appl. Phys. 108, 113504 (2010).

[53] S.-Y. Seo, H.-S. Han, and J. H. Shin, J. Korean Phys. Soc. 39, S78 (2001).

[54] S. Saito, T. Takahama, K. Tani, M. Takahashi, T. Mine, Y. Suwa, and D. Hisamoto, Appl. Phys. Lett. 98, 261104 (2011).

[55] L. Ding, M. B. Yu, X. Tu, G. Q. Lo, S. Tripathy, and T. P. Chen, Opt. Express 19, 2729 (2011).

[56] R. Pratibha Nalini, L. Khomenkova, O. Debieu, J. Cardin, C. Dufour, M. Carrada, and F. Gourbilleau, Nanoscale Res. Lett. 7, 124 (2012). 